\title{
Challenges posed by and approaches to the study of seasonal-to-decadal climate variability
}

\author{
Cornelia Schwierz • Christof Appenzeller • \\ Huw C. Davies • Mark A. Liniger · Wolfgang Müller • \\ Thomas F. Stocker · Masakazu Yoshimori
}

Received: 9 December 2004 / Accepted: 14 December 2005 / Published online: 4 November 2006

(C) Springer Science + Business Media B.V. 2006

\begin{abstract}
The tasks of providing multi-decadal climate projections and seasonal plus subseasonal climate predictions are of significant societal interest and pose major scientific challenges. An outline is presented of the challenges posed by, and the approaches adopted to, tracing the possible evolution of the climate system on these various time-scales. First an overview is provided of the nature of the climate system's natural internal variations and the uncertainty arising from the complexity and non-linearity of the system. Thereafter consideration is given sequentially to the range of extant approaches adopted to study and derive multi-decadal climate projections, seasonal predictions, and significant sub-seasonal weather phenomena. For each of these three time-scales novel results are presented that indicate the nature (and limitations) of the models used to forecast the evolution, and illustrate the techniques adopted to reduce or cope with the forecast uncertainty. In particular, the contributions (i) appear to exemplify that in simple climate models uncertainties in radiative forcing outweigh uncertainties associated with ocean models, (ii) examine forecast skills for a state-of-the-art seasonal prediction system, and (iii) suggest that long-lived weather phenomena can help shape intra-seasonal climate variability. Finally, it is argued, that coconsideration of all these scales can enhance our understanding of the challenges associated with uncertainties in climate prediction.
\end{abstract}

C. Schwierz $(\bowtie) \cdot$ H. C. Davies

Institute for Atmospheric and Climate Science, ETH Zürich, Switzerland

e-mail: cornelia.schwierz@env.ethz.ch

C. Appenzeller · M. A. Liniger · W. Müller

Federal Office of Meteorology and Climatology (MeteoSwiss), Switzerland

W. Müller

Present Address: MPI for Meteorology, Hamburg, Germany

T. F. Stocker · M. Yoshimori

Climate and Environmental Physics, Physics Institute, University of Bern, Switzerland

M. Yoshimori

Present Address: Center for Environmental Prediction, Rutgers University, USA 


\section{Introduction}

In the context of possible anthropogenically-induced climate change considerable effort is being devoted to providing projections of the evolution of the climate system over the $21 \mathrm{st}$ century (e.g., IPCC 2001). These projections should in principle not only yield an indication of the development of a climate mean but also supply the associated behaviour of and change of that variability (e.g., Mearns et al. 1984; Schneider 2000). Indeed it is possible that climate change could be manifested at least in part by changes in the nature and amplitude of the variability. Thus it is important to improve both our understanding and our predictive capability of climate variability.

Here the focus is on the atmospheric component of the climate system and on multidecadal, seasonal, and sub-seasonal time-scales. In this time-range key processes influencing the variation and change range from the direct and indirect effects of increased greenhouse gas emissions, the longer-term memory of the oceans, atmosphere-ocean and atmosphere-land surface interactions, and the internal dynamics of the atmosphere itself.

In the following sections, an overview is provided of the challenges associated with developing projections on these different time-scales. In Section 2 summaries are given of the concepts of climate variability; the prediction-model hierarchy; forecast uncertainty and the probabilistic approach to quantify forecast uncertainty. The subsequent sections are devoted to consideration of the methods and challenges pertaining to each time-scale, and providing novel results that exemplify the complexity and temporal interrelations and specific intricacies. The individual sections comprise a discussion of the utility of a hierarchy of climate models to reduce the uncertainty of climate projections on the multi-decadal time scales (Section 3); the ingredients of current schemes for seasonal prediction and the quantitative assessment of forecast skill (Section 4); and a discussion of the dynamics of significant sub-seasonal weather phenomena and their linkage to climate variation (Section 5). Finally some comments are proffered on the synergies that exist between the procedures employed on these different time-scales and possible avenues for future research (Section 6).

\section{Basic concepts}

\subsection{Climate variability, impacts and trends}

Climate varies naturally on a vast range of time-scales under the influence of both external forcing or internal variability of the system. Internal variability occurs, because in a system of components with non-linear interactions and very different response times the components tend to vary constantly and not achieve a state of inter-component equilibrium. The response of the climate to external forcings and to the internal variability is further complicated by feedbacks and non-linear responses of the components (IPCC 2001). On the regional scale, climate variability often manifests itself in geographically anchored spatial patterns with changing amplitude (and sign). These patterns determine the local climatic conditions and hence it is also highly desirable to understand and predict them accurately.

The strongest large-scale climate variation on seasonal to inter-annual time-scales has its origin in the tropical-subtropical Pacific and is known as the El Niño/Southern Oscillation (ENSO, see reviews of Philander 1990; Trenberth et al. 1998), that typically occurs every 2-7 years. The ENSO phenomenon consists of a coupled interplay between the atmosphere and ocean. It is associated with a see-saw in atmospheric pressure between the eastern and western Pacific and the occurrence of warm ocean-temperature anomalies in the upper few hundred 
meters of the eastern and central tropical Pacific. Marked shifts in weather conditions, in particular precipitation patterns, are associated with ENSO and are not only located in the central Pacific, but also over adjacent continents (Trenberth and Hurrell 1994) and in more removed regions around the globe (Diaz and Markgraf 2000). For Europe there is only a limited direct impact of the equatorial Pacific (Fraedrich 1994; van Oldenborgh et al. 2000; Merkel and Latif 2002), and it has nonlinear (Lin and Derome 2004) and nonstationary (Greatbatch et al. 2004) characteristics.

In the North-Atlantic European area other climate variations such as the North Atlantic Oscillation (NAO) have more substantial impact (for a detailed review see Hurrell et al. 2003 and references therein). Indeed, the NAO is the major winter climate mode, accounting for about one third of the statistically derived inter-annual variability of the mid-tropospheric large-scale flow in mid-latitudes. It is often defined with an index based upon the sea-level pressure anomaly difference between the Azores and Iceland. During the positive phase, a stronger south-westerly flow advects warmer and humid air towards Northern Europe. In the negative phase, the flow is weaker and more zonally oriented. The NAO provides a statistically well-defined pattern to study the predictability of the European winter climate. Unlike the impact of ENSO on the Pacific-American sector, the processes determining the evolution of the NAO remain controversial (Hurrell et al. 2003). In addition, the higher modes of variability are significant for the local climatic variations in the Euro-Atlantic sector (e.g., Pavan et al. 2000b; Scherrer et al. 2006). Most of the existing studies on the mechanisms behind Euro-Atlantic climate variability have however focussed on explaining NAO variability.

Evidence indicates that most of the NAO variability evolves from internal non-linear extratropical atmospheric dynamics. The autocorrelation of the NAO index exhibits a de-correlation time-scale of 8-10 days (Stephenson 2000; Feldstein 2000), and this can be viewed as the fundamental time scale for the short-term NAO component. In this context the long-lived synoptic phenomena (weather regimes) can modulate the seasonal or monthly-mean flow pattern. An example of such a weather phenomenon is atmospheric blocking, i.e. long-lasting quasistationary high-pressure systems with typical life-times of 7-15 days (e.g., Croci-Maspoli et al. 2006). On longer time-scales, these weather components exhibit little coherence and it has been cautioned that the observed longer-term NAO fluctuations might be the statistical residue of the averaged short-term contributions (Wunsch 1999; Stephenson 2000). However, this so-called "climate noise paradigm" (Leith 1973; Hasselmann 1976; Madden 1976) falls short of explaining the increased winter NAO variability of the last decades of the 20th century (see Hurrell et al. 2004 and references therein). Hurrell et al. (2004) attribute it to a combination of a tropically forced signal and a "noise" component, and Gillett et al. (2003) hypothesise that the observed positive trend of the NAO over the last 30 years is attributable to the increasing concentration of atmospheric greenhouse gases (GHGs). ${ }^{1}$ Potentially relevant one-way or coupled interactions with other components of the climate system include (i) the mid-latitude ocean (see Bjerknes 1964; Rodwell et al. 1999 and others), (ii) the tropical ocean (Hoerling et al. 2001; Bader and Latif 2003), (iii) the Indian ocean (Hurrell et al. 2004), and (iv) the stratosphere (Thompson and Wallace 2001; Baldwin and Dunkerton 2001). There are decadal signals in the NAO variability (Appenzeller et al. 1998), and the detection of such long-term trends and variability must rely on observations and proxy historical reconstructions (Luterbacher et al. 2002). Model simulations in unforced control conditions

\footnotetext{
${ }^{1}$ Viewed in perspective of the latest NAO data up to 2004/05 Gillett's hypothesis probably needs to be modified (C. Deser, pers. comm.).
} 
can help decide whether the observed recent trends might merely be irregular events. To further resolve questions of this nature, a hierarchy of models needs to be developed and employed.

\subsection{Remarks on the complexity of the model hierarchy}

The choice of the prediction model and its degree of complexity depends on both the scientific focus and the available computational resources. This dichotomy influences the selection of the range of processes, the climate components, the parametrized processes and the model resolution. A whole range of models of varying complexity exists and the most commonly applied categories and their specific properties are introduced here.

Dynamical models are founded on the physical laws that govern the oceanic and atmospheric system and are designed to simulate weather or climate on a range of spatial and temporal scales, by solving numerically the governing fluid-dynamic and thermodynamic equations. Unresolved processes in such models (e.g. cloud microphysics, convection) are represented by grid-box parametrisations or introduced by empirical statistical relationships. The model hierarchy comprises three main types of models:

(i) For numerical weather prediction (NWP) up to the 5-10 day scale, the ocean component is often treated as merely a fixed lower boundary or represented in a slab-type manner, whereas the dynamics of the atmosphere is represented in some considerable detail. Current NWP models operate at horizontal resolutions of $\sim 7 \mathrm{~km}$ (regional) and $\sim 50 \mathrm{~km}$ (global). On the weather time scale, the sea surface temperature (SST) variability is mainly a result of the surface wind stress.

(ii) For seasonal prediction an improved representation of the ocean processes is necessary. Both NWP models of slightly coarser spatial resolution and atmosphere-ocean general circulation models, AOGCMs, are employed, with a dynamical ocean coupled to the atmosphere and often a refined parametrisation of land surface processes. Currently seasonal predictions are conducted at ECMWF ${ }^{2}$ at $\sim 150 \mathrm{~km}$ resolution for both atmosphere and ocean. The limited resolution of such a global description of the coupled system requires a reduction in complexity with a focus on the processes thought to be most relevant for the corresponding spatial and temporal scales.

(iii) In modelling past and future climate on time scales of many decades to centuries the synoptic-scale weather is invariably regarded as a noise component, whereas the ocean is accorded high spatial resolution, of currently $\sim 100-300 \mathrm{~km}$ (e.g. OGCMs). Projections on decadal to century time-scales are usually undertaken in the following sequence of steps: (1) construction of emission scenarios for the various radiatively active species; (2) translation of the emissions to the atmospheric concentrations using gas-cycle and chemistry-transport models, and then, if necessary, to radiative forcing or albedo; and (3) projection of the forcing on climate using comprehensive three-dimensional climate models (IPCC 1990, 1996, 2001).

For even longer time scales, the complexity of models is systematically reduced (e.g. by averaging certain dimensions in space). This leads to the formulation of climate models of reduced complexity (Stocker et al. 1992), or Earth System Models of Intermediate Complexity (EMICs, Claussen et al. 2002). A reduction in complexity or resolution decreases the computational demands (see also Stocker and Marchal 2001; Claussen et al. 2002; Stocker and Knutti 2003), and can be prompted by physical considerations based upon the relative importance of the physical processes. However the presence of non-linear and inter-scale

\footnotetext{
${ }^{2}$ European Center for Medium-Range Weather Forecasts. 
interactions can render this procedure questionable, unless careful and specific comparisons with models of higher complexity are undertaken.

Dynamical models explicitly use the physical equations and thereby attempt to accurately capture events in terms of their physical causes and effects. In contrast statistical models do not seek to represent physical processes. Statistical models are essentially based upon exploiting long observational data sets to identify key relationships between the ocean and atmosphere in the past. They range from simple approaches that refine persistence (Colman and Davey 2003), analogue or linear regression techniques, sophisticated schemes utilising nonlinear canonical correlation analysis, and probabilistic schemes (Mason and Mimmack 2002) or Markov chains (Pasmanter and Timmermann 2003). A comprehensive comparison of results derived using these various approaches to forecast one particular event - the 1997/98 ENSO event - is given by Barnston et al. (1999a) and Landsea and Knaff (2000).

Most statistical models are based on the stationarity assumption and imply that the governing processes do not change with time and retain their statistical characteristic in principle into the future. Therefore, such statistical models cannot be employed to study the functioning of climate change processes and are strongly limited in anticipating unexpected changes in the climate system. Further, these models typically tend to be designed and trained for one particular quantity and time-scale in one particular location (e.g. ENSO index). Dynamical models require the initial state of the climate system with an accuracy as high as possible, while statistical models are based on a high-quality historical record.

To summarise, the prediction and validation of climate variability for each scale is beset with its own characteristic difficulties. Computational costs are linked to the degree of the model's comprehensiveness in representing the primary physical processes and their spacetime resolution. It is important to note however, that there are limits to the reduction of complexity for an adequate representation of climate variability, e.g. the need to represent as realistically as possible atmospheric transients in climate experiments.

\subsection{Types of uncertainty}

Foundational to the assessment of climate projections is the recognition that they are linked to various intrinsic and inevitable uncertainties (Reilly et al. 2001; Allen et al. 2001), and below we set out the rudiments of three types. Together the three sources of uncertainty contribute to the uncertainty of a prediction (cf. Figure 1).

Type I uncertainty relates to the selection or construction of emission scenarios and the implications for the radiative forcing and is mainly relevant for decadal to centennial climate projections (cf. for instance Sutton 2005). Nakićenović et al. (2000) proposed 40 different emission scenarios (SRES) that were to be viewed as "images of how the future might unfold". The scenarios took into account "demographic development, socio-economic development, and technological change" (although no political intervention), but "probabilities or likelihood were not assigned to individual scenarios". For 35 selected scenarios the total radiative forcing from 1990 to 2100 ranges from about 3.1 to $8.1 \mathrm{Wm}^{-2}$ (Wigley and Raper 2001). Thus differing emission scenarios result in uncertainty related to radiative forcing. However the absence of an assigned probability to the scenarios makes it difficult to quantify the uncertainty (Schneider 2001; Grübler and Nakicenovic 2001), and the high dimensionality of the phase space militates simulating all possible settings with GCMs.

Type II uncertainty is linked directly to the nature of the climate system. The system is highly non-linear and its evolution is irregular, and forecasts are subject to imperfectly known initial and boundary conditions. Slightly different representations of the initial state or forcing 


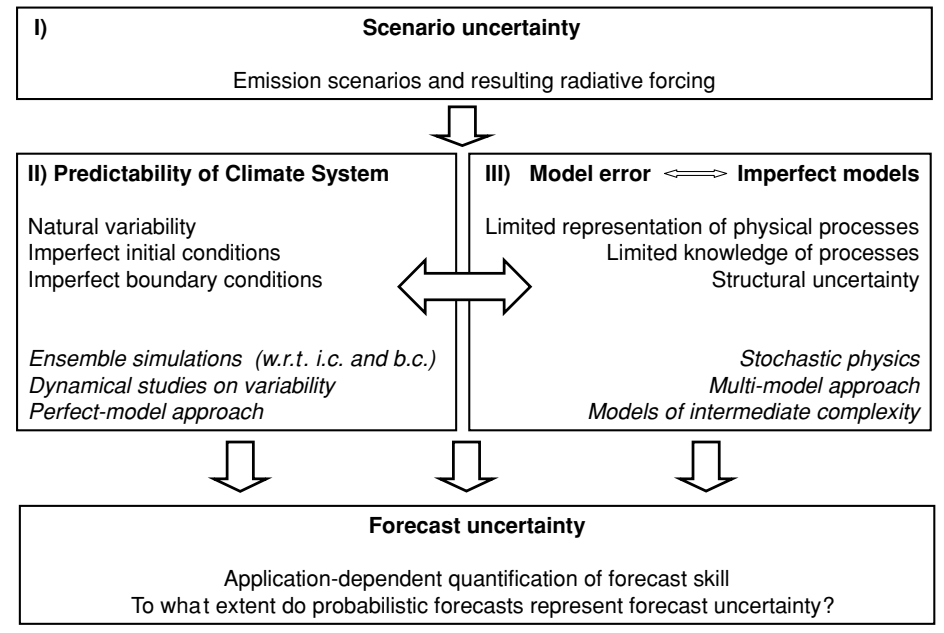

Fig. 1 Schematic illustration of the three components of forecast uncertainty (bold), that are discussed in Section 2.3. The assigned keywords refer to the contributions of each type. Also mentioned are some modelling approaches and related research areas (italic) that are elaborated further in Sections 3 to 5 . Refer to text for details

can lead to very different but equally feasible projections into the future. A preliminary estimate of the climate sensitivity to a change in an individual forcing can be obtained by measuring the impact upon some pertinent parameter. ${ }^{3}$ Cubasch et al. (2001) calculate climate sensitivity from 15 atmospheric GCMs coupled to mixed-layer ocean models. The resulting values range from 2.0 to $5.1^{\circ} \mathrm{C}$, and their final estimated values based on "expert elicitation" range from 1.5 to $4.5^{\circ} \mathrm{C}$. Such an estimate of this type of uncertainty is neither fully objective nor is it accompanied by probabilistic representations. Moreover (cf. Section 2.1), the climate system exhibits an intrinsicly chaotic behaviour. Hence climate variability is often sustained by stochastic, unpredictable or unresolved processes. The degree of forecast uncertainty is dependent on the actual state of the atmosphere, i.e. modulated by natural climate variability.

Type III arises from the fact that the representation of the climate system in a weather or climate model is inevitably incomplete and inadequate. The models carry uncertainty due to (i) the chosen formulation of model equations of the prediction models themselves (socalled structural uncertainty); (ii) the limited representation of physical processes, e.g. due to resolution or due to our limited knowledge of the relevant processes and (iii) the non-linear interactions between climate components themselves. The complexity of the climate system (type II) and the model imperfection (type III) are thus intimately linked.

For type III uncertainty due to an imperfect knowledge of processes can be exemplified by the estimation of the radiative forcing. For the well-mixed greenhouse gases (GHGs) the radiative forcing from pre-industrial to present can be inferred with a relatively high confidence. However the forcing due to other radiatively active species is not well constrained (Ramaswamy et al. 2001). In particular, the radiative forcing due to the indirect effects of tropospheric aerosol has the largest uncertainty (Haywood and Boucher 2000; Knutti et al. 2002;

\footnotetext{
${ }^{3}$ For instance the equilibrium climate sensitivity to $\mathrm{CO}_{2}$ changes is defined as the equilibrium response of the global mean temperature to the forcing that results from a doubling of the atmospheric $\mathrm{CO}_{2}$ concentration. It is inversely proportional to the strength of the feedback processes in the system that act to counter a change in forcing IPCC:1990,IPCC:1996,IPCC:2001.
} 
Anderson et al. 2003a), followed by mineral dust (Ramaswamy et al. 2001). Ramaswamy et al. (2001) presented the uncertainty range for the indirect effect of tropospheric aerosol as -2 to $0 \mathrm{Wm}^{-2}$, with an extreme value being nearly comparable in magnitude to the GHG radiative forcing of $2.4 \mathrm{Wm}^{-2}$. This uncertainty originates essentially from the combination of a lack of global and long-term observations and a poor understanding of the underlying processes. Uncertainties in other forcings such as the direct effect of tropospheric aerosols and tropospheric ozone could be similarly large if they are added together (IPCC 2001).

Together these three types of uncertainty place a limit upon the predictability of the system and determine the reliability of the prediction.

\subsection{Probabilistic forecasts, errors and uncertainty}

In view of the foregoing it is highly desirable to quantify the forecast uncertainty (Palmer et al. 2005) and to assess the flow-dependent predictability of the atmosphere-climate system. To this end it has become customary to produce probabilistic estimates of the projected development. A traditional deterministic forecast given by a certain value for the predicted quantity (e.g. temperature will be $25^{\circ} \mathrm{C}$ ) carries no information on the uncertainty. In contrast, probabilistic forecasts can provide a quantitative indication of the level of uncertainty inherent in the prevailing climatic configuration. They usually result in an estimate of the probability density function (PDF) for the predicted quantity (e.g. a forecast histogram for temperature) or the probability for the incidence of a particular event (e.g. probability for the temperature to be above $25^{\circ} \mathrm{C}$ ). Provided an estimate is available of the range of uncertainty in input (e.g. emissions) and model parameters, the strategy is to try and cover the largest possible area of model phase space so as to provide probabilistic estimates of a projected development.

A probabilistic forecast can be obtained in various ways. (i) Statistical forecasting systems can be set up not only for the mean tendency but also for a direct prediction of the PDF moments. However, this requires the derivation of equations governing the evolution of the mean and higher-order statistical moments, and moreover the interdependency of the moments poses difficulties regarding the cut-off (i. e. the closure problem), cf. Ehrendorfer 1997 and references therein. (ii) Sampling the PDF by multiple integrations of the prediction model. This ensemble strategy (e.g., Palmer 1993; Palmer et al. 2005) requires performing a large number of model runs with slightly altered conditions so as to mimic the forementioned uncertainties (I)-(III). Specifically, single-model ensembles can be obtained by multiple integrations with slightly different initial and boundary conditions. This approach provides information on the single-model prediction uncertainty from uncertain starting conditions (Tracton and Kalnay 1993; Palmer and Anderson 1994; Stern and Miyakoda 1995). Additionally, the uncertainty due to unresolved processes can be described by introducing a stochastic component during the integration (Buizza et al. 1999) or by implementing socalled stochastic-dynamic subgrid models (Palmer et al. 2005). The degree of inter-model uncertainty can be assessed by comparing results obtained with different models (multi-model ensemble). This has been a key feature of successive IPCC assessments. (iii) Assigning an error bar to each variable and process. This requires tracing the evolution of the assigned error bars with the dynamical equations to derive a non-linear estimate of the uncertainty range (forward modelling, cf. Section 3.3). This approach is difficult when non-linear interactions dominate and it is also not trivial to estimate the (model dependent) error bars.

Available computer resources limit the use of comprehensive climate models to obtain single-model ensemble runs to evaluate their sensitivity to the representation or specification of particular processes. However complementary strategies can be adopted to at least partially circumvent this shortcoming. First a novel approach geared to exploiting the computational 
resources available via grid computing (Allen 1999; Allen and Stainforth 2002; Stainforth 2005) enables ensemble simulations to be undertaken with a single but relatively complex GCM using differing physical parametrizations (cf. Section 3.2). Second a somewhat more simplified climate model with less detailed physical representations and spatial resolution that is concomitantly much more computationally efficient can be deployed in an ensemble mode (cf. Section 3.3).

However, one should be aware that the error and uncertainty estimates are obtained in the self-contained model world. This prompts the caveat "Can we estimate the uncertainty in our uncertainty estimates? [...] Ultimately, all uncertainty is quantified within a given modeling paradigm and our forecasts need never reflect the uncertainty in a physical system." (Smith 2002).

Finally note that quantitative information on the uncertainty can be crucial for many end-user applications. The intrinsic dynamic predictability limit of the atmosphere must be sharpened or tailored to match the end-users' needs, since different applications often depend upon and require different metrics of uncertainty. More details on ensemble forecasting and the definition of model skill is outlined in Section 4.2.

In the subsequent sections consideration will be given sequentially to the range of extant approaches adopted to derive multi-decadal climate projections, seasonal predictions, and sub-seasonal weather phenomena that significantly contribute to seasonal climate variability. For each of these three time-scales novel results are presented that give an indication of the nature (and limitations) of the models used to forecast the evolution, and the techniques adopted to reduce or cope with the forecast uncertainty.

\section{Multi-decadal climate projections, models and uncertainty}

In this section the focus is on climate projections for decadal and centennial time-scales. Particular attention is devoted to the deployment of a hierarchy of climate models to assess and reduce the uncertainty that accompanies such predictions, and the results derived with such a hierarchy can in principle increase our understanding of model uncertainties provided care is excersised in their interpretation.

\subsection{Models of reduced complexity}

Figure 2 provides an overview of both the atmosphere and ocean component of a hierarchy of models of varying complexity. Notwithstanding the caveats of reduced complexity models mentioned in Section 2.2, a range of these models have been and are currently used to study specific aspects of the climate system and to examine the accompanying sensitivity (cf. Figure 2). Examples are energy balance models (EBMs), radiative-convective models (RCMs), statistical dynamical models (SDMs), and quasi-geostrophic (QG) models. EBMs are based on vertically-integrated energy balance equations, and further averaging may be made in horizontal directions (e.g., Budyko 1969; Sellers 1969; North et al. 1981). They may also include a moisture balance equation when coupled to ocean models. Transport in EBMs is usually parametrised by eddy diffusion. RCMs solve vertical radiative energy transfer equations with a prescribed convective adjustment scheme deployed to maintain vertical stability (e.g., Manabe and Strickler 1964; Manabe and Wetherald 1967; Ramanathan and Coakley 1978). SDMs employ somewhat more sophisticated parametrisations than EBMs and represent the statistical behaviour of synoptic-scale processes with empirically-based Springer 


\begin{tabular}{|c|c|c|c|c|c|}
\hline \multirow{2}{*}{\multicolumn{2}{|c|}{ Dimension }} & \multicolumn{4}{|c|}{$\boldsymbol{O} \boldsymbol{e} \boldsymbol{e} \boldsymbol{a}$} \\
\hline & & $\mathbf{0}$ & 1 & 2 & 3 \\
\hline \multirow{4}{*}{$\begin{array}{l}0 \\
0 \\
0 \\
0 \\
0 \\
0 \\
0 \\
5 \\
5 \\
1\end{array}$} & $\mathbf{0}$ & $\begin{array}{c}\text { global EBM } \\
\text { Saltzman-type models } \\
\text { pulse response models } \\
\text { neural network }\end{array}$ & $\begin{array}{c}\text { global mixing models } \\
\text { geochemical box models } \\
\text { UD/EB models } \\
\text { MAGICC, HILDA}\end{array}$ & $\begin{array}{c}\text { THC models (lat/z) } \\
\text { wind-driven circulation } \\
\text { models (lat/long) } \\
\text { deep ocean models } \\
\text { (lat/long) }\end{array}$ & OGCM \\
\hline & 1 & $\begin{array}{l}\text { EBM (lat) } \\
\text { RCM (z) }\end{array}$ & - & $\begin{array}{c}\text { ocean }(\text { lat } / \mathrm{z})+\mathrm{EBM}(\text { lat }) \\
\text { Bern 2.5D }\end{array}$ & - \\
\hline & 2 & EBM (lat/long) & $\begin{array}{l}\text { SDM }(\text { lat } / z)+\text { diffusion } \\
\text { ocean, } \boldsymbol{M I T} 2-\boldsymbol{D}\end{array}$ & $\begin{array}{l}\text { ocean (lat } / \mathrm{z})+ \text { SDM } \\
\text { (lat } / \text { long), CLIMBER-2 } \\
\text { ocean (lat } / \mathrm{z})+ \text { QG atm. } \\
\text { (lat } / \mathrm{z}), \text { MoBidiC }\end{array}$ & $\begin{array}{l}\text { OGCM }+ \text { EBM (lat/long) } \\
\boldsymbol{U} \boldsymbol{V i c} \\
\text { FG ocean }+ \text { EBM (lat/long) } \\
\text { Bern3D }\end{array}$ \\
\hline & 3 & $\mathrm{AGCM}+\mathrm{SST}$ & - & $\mathrm{AGCM}+$ mixed layer & $\begin{array}{c}\text { QG atm. + QG ocean } \\
\boldsymbol{Q} \text { - } \boldsymbol{G C \boldsymbol { M }} \\
\text { QG atm. + OGCM } \\
\boldsymbol{E} \boldsymbol{c} \boldsymbol{B} \text { ilt } \text { - } \boldsymbol{C L I} \boldsymbol{O} \\
\text { A/OGCM }\end{array}$ \\
\hline
\end{tabular}

Fig. 2 A hierarchy of climate models and their substitutes categorised in terms of resolved spatial dimensions in atmosphere and ocean components. The names of specific models are given in bold italics. The table is intended to present examples of existing models and is not complete. Abbreviations are explained in the text. Modified from Stocker and Knutti (2003)

relations (e.g., Saltzman 1978). A rigorous approximation to the dynamical equations is made in QG models (e.g., Gallée et al. 1991; Opsteegh et al. 1998; Hogg et al. 2003).

Examples of ocean model components of reduced complexity are 1-D upwelling-diffusion (UD) models and zonally averaged thermohaline circulation (THC) models (e.g., Marotzke et al. 1988; Wright and Stocker 1991). Examples of dynamically simplified 3-D models are frictional geostrophic (FG) models (e.g., Maier-Reimer and Mikolajewicz 1992; Edwards and Marsh 2005; Müller et al. 2005) and QG models (e.g., Hogg et al. 2003).

In some applications, substitutes of climate models are used that take the form of pulse response models. The latter assume a linearity of the response but dramatically increase the computational efficiency (Joos and Bruno 1996). Alternatively a neural-network approach formally removes the linearity assumption but does not necessarily replicate the system's non-linear characteristics (Knutti et al. 2003).

In the next sub-sections we review approaches of assessing uncertainty using models of different complexity.

\subsection{Uncertainty assessment with GCMs}

Beyond observational validation of individual models there have been concerted international efforts to evaluate the performance of GCMs with model intercomparison projects. Such projects involve the coordinated conduct of experiments, and examples include atmospheric GCM simulations with prescribed, historical sea surface conditions (AMIP, cf. Gates et al. 1999) and coupled GCM simulations with a historical, scenario, or idealized forcing (CMIP, cf. Covey et al. 2003). These studies reveal the range, similarities and differences in model behaviour and help to pinpoint the important processes whose better representation can improve GCMs. While such an approach is fundamental to capture the structural uncertainty 
(see type III, Section 2.3), it is not designed to assess parametric uncertainty (the uncertainty associated with model parameter values).

Parametric uncertainty was systematically investigated by Murphy et al. (2004) in a single atmospheric GCM coupled to a mixed-layer ocean model. It involved an ensemble simulation of the present-day climate with 53 different model set-ups with 29 key parameters being varied separately. The relative reliability of different model set-ups was assessed based on the deviation of simulated climate from observations. Climate sensitivity (cf. 2.3) was then estimated by linearly combining the climate feedback parameters, weighted according to the models' "diagnosed" reliability. A PDF of climate sensitivity was obtained from $\sim 10^{6}$ random combinations of values for the model parameters. With this observational constraint the $5-95 \%$ confidence interval of climate sensitivity narrowed from $1.5-5.3{ }^{\circ} \mathrm{C}$ to $2.4-5.4{ }^{\circ} \mathrm{C}$. However the validity of the linear combination of climate feedback parameters can be questioned (Stainforth 2005), and on the basis of results with a "grand ensemble" of 1000 GCM simulations a case can be made for a much wider range of climate sensitivity, $1.9-11.5^{\circ} \mathrm{C}$. A caveat is that the latter range was not constrained by observations and hence reflects simply the à priori PDFs.

Allen et al. (2000) and Stott and Kettleborough (2002) evaluated the uncertainty in predictions of future warming by using an empirical linear relationship between the 20th century and the mid-21st century warming in models with a hierarchy of complexities. The mid-21st century warming is scaled based on the simulated 20th century warming so that the latter becomes consistent with observations. This scaling was done in a reduced spatio-temporal space applying optimal fingerprinting (or optimal detection method; cf. Weaver and Zwiers 2000; Zwiers 2002). The strength of the method is that the prediction is minimally affected by the uncertainty in climate sensitivity and ocean heat uptake. In other words, the models are not required to simulate the amplitude of the response accurately, but merely its structure. A limitation is that this approach is not applicable if for example the balance between GHG and sulphate aerosol forcing changes with time. In addition, the projection does not take into account the abrupt climate change that could result from non-linear effects. Furthermore, the method cannot, by design, account for the forcing uncertainty. In summary, significant progress has been made during the last few years in the assessment of uncertainty with GCMs despite the obstacle posed by the severe computational cost of those models.

\subsection{Uncertainty assessment with reduced complexity models}

\subsubsection{Forward modeling to assess uncertainty}

To provide a probabilistic "guidance" to the estimates given in Cubasch et al. (2001), Wigley and Raper (2001) assigned, based on IPCC (2001), PDFs to input and model parameters that have large uncertainty: aerosol forcing, climate sensitivity, ocean vertical diffusivity, and carbon cycle feedback. The procedure followed was to integrate a UD/EB model with various combinations of parameters $\left(\sim 10^{6}\right.$ simulations in total $)$ to yield PDFs for the future temperature change. With an estimated 5-95\% confidence interval of warming from 1990 to 2100 the change ranges from 1.7 to $4.9^{\circ} \mathrm{C}$. Note however that the derived uncertainty range mainly reflects the subjectively determined à priori PDFs of input and model parameters, and hence is not an objective quantity. In addition, the absence of ocean and atmospheric dynamics in the model set-up limits determination of the full uncertainty. 


\subsubsection{Inverse modeling to assess uncertainty}

The application of inversion procedures are common in many geophysical settings. Typically they involve the estimate of unknown parameters of a system with given input and output, or an estimate of the input with given system and a known output. For linear systems a direct inversion is often possible. However one has to adopt the approach of indirect inversion if the system is non-linear (e.g. the climate system), or if neither the input nor parameters are known (e.g. sulphate aerosol forcing and ocean mixing parameters). In a climate modelling setting this entails adjusting the unknown parameter values to minimise the residuals ( - difference between the simulated and observed values) by repeatedly performing forward simulations. In effect observations are used to constrain the range of unknown or uncertain parameters using the so-called Bayesian approach. This approach requires, by design, a large number of ensemble members, and current computational cost prohibits its application to coupled GCMs. An example with a reduced complexity model will be given later (Section 3.4).

Recently, several studies with different types of reduced complexity models exploited the inverse approach to assess the uncertainty associated with radiative forcing, climate sensitivity, and ocean mixing. Andronova and Schlesinger (2001) used a similar type of model as Wigley and Raper (2001), and conducted $\sim 10^{4}$ simulations. Using mean and interhemispheric difference in near-surface air temperature as constraining variables, the estimated 5-95\% confidence interval for total sulphate aerosol forcing and climate sensitivity range from -0.54 to $-0.13 \mathrm{Wm}^{-2}$ and 1.0 to $9.3^{\circ} \mathrm{C}$, respectively. Forest et al. (2002) used a zonally averaged 2-D SDM coupled to a mixed-layer ocean model in which temperature anomalies diffused into the deep ocean, and conducted $\sim 10^{1}$ simulations. Using latitudeheight air temperature, and global mean near-surface air temperature and ocean heat uptake as the constraining variables, the estimated 5-95\% confidence intervals for total anthropogenic aerosol forcing, climate sensitivity, and effective ocean diffusivity range from -0.3 to 0.95 $\mathrm{Wm}^{-2}, 1.4$ to $7.7^{\circ} \mathrm{C}$, and $1.8 \times 10^{-4}$ to $56.0 \times 10^{-4} \mathrm{~m}^{2} \mathrm{~s}^{-1}$, respectively. Knutti et al. (2002) used a similar model as Stocker and Schmittner (1997), and conducted $\sim 10^{4}$ simulations. Using global mean observational records of both near-surface air temperature and ocean heat uptake as constraining variables, their estimated 5-95\% confidence interval for indirect aerosol forcing ranges from -1.2 to $0 \mathrm{Wm}^{-2}$. The a priori uncertainty range for climate sensitivity from 1 to $10^{\circ} \mathrm{C}$ was not narrowed. The number of ensemble members can be increased to the order of $\sim 10^{6}$ by introducing a neural network to serve as a model substitute (Knutti et al. 2003). Noting that indirect aerosol forcing has the largest uncertainty among radiative forcing agents, the results of the latter studies constitute a reduction in the uncertainty of this effect in comparison to the forward modeling approach (Anderson et al. 2003a). However these studies do not place a strong constraint upon the climate sensitivity and the value of the ocean mixing parameter with the given large uncertainties in forcing.

\subsubsection{Ensemble kalman filtering}

As noted earlier there are large uncertainties associated with the representation of unresolved processes in climate models. Annan et al. (2005) and Hargreaves et al. (2004) applied a data assimilation technique with an ensemble Kalman filter to derive an objective estimate of uncertainty in parameters of a 3-D FG ocean model coupled to a 2-D EBM. In the usual data assimilation framework, state variables such as temperature and salinity were adjusted to minimise the difference between simulations and observations (i.e. the residuals) at every assimilation point. This adjustment results in state variables 'approaching' observations. The relation between model parameter values and the residuals were obtained by conducting 
an ensemble simulation with different parameter sets. In turn this information was used to update or adjust the model parameters towards optimal values so that residuals are minimised. In these studies, the modern steady state is considered to constrain 12 model parameters. The advantage of this method is that it requires a moderate number of ensemble members of 54 although the sensitivity of the results to this number is not presented. The method was shown to be orders of magnitude more efficient than the 1000-member Monte Carlo simulations of Edwards and Marsh (2005). An ensemble simulation with the estimated model parameter uncertainty range under a generic $1 \%$ annual increase of atmospheric $\mathrm{CO}_{2}$ exhibits a qualitatively similar spread of future THC as Knutti and Stocker (2002).

\subsection{Reduction of uncertainty}

The Bayesian approach applied to reduced complexity models is a powerful tool to assess the uncertainty in forcing and model parameters. Moreover the availability of more observational data in the future will serve to constrain more tightly the uncertain parameters and thereby result in a reduction in the corresponding value of the uncertainty.

To demonstrate this possibility, we extend the ensemble approach of Knutti et al. (2002) using a global EBM coupled to a 1-D diffusion ocean model. The concept of the experiment is schematically depicted in Figure 3. It entails four steps. First, the model is integrated to obtain a surrogate of observational records from 1765 to 2100, and thereafter an uncertainty range is added to this 'true record' by assuming a reasonable magnitude for the internal variability. Second, à priori PDFs are assigned for climate sensitivity, ocean vertical diffusivity, and radiative forcing based on IPCC (2001) as in Knutti et al. (2002). Third, 10,000 model simulations are performed to obtain à posteriori PDFs for parameters that are consistent with the observational substitute. Fourth, future forcings are projected using the posteriori PDFs to obtain PDFs of future warming. Figures $4 a$ and $b$ show the PDFs of future warming for

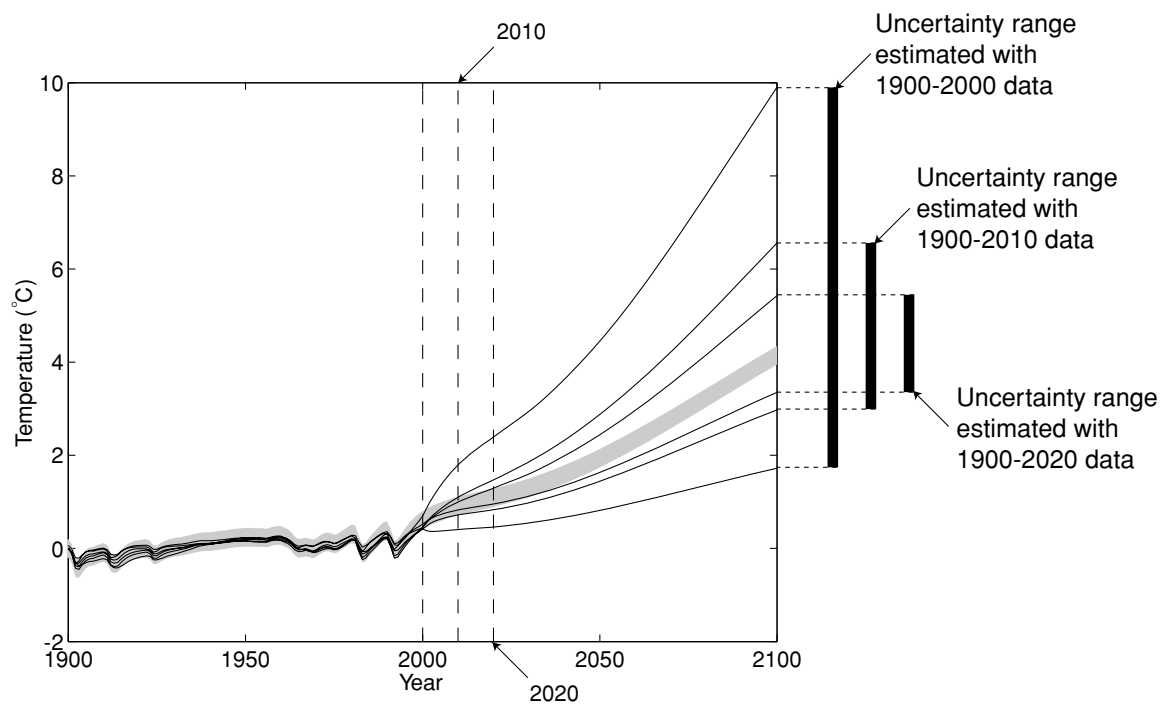

Fig. 3 Schematic diagram of the 'perfect model' experiments in demonstrating the reduction of uncertainty assuming the existence of longer observational records. Each thin curve represents an ensemble member. Shading represents the sum of an observational substitute ('true answer') and assumed internal variability 

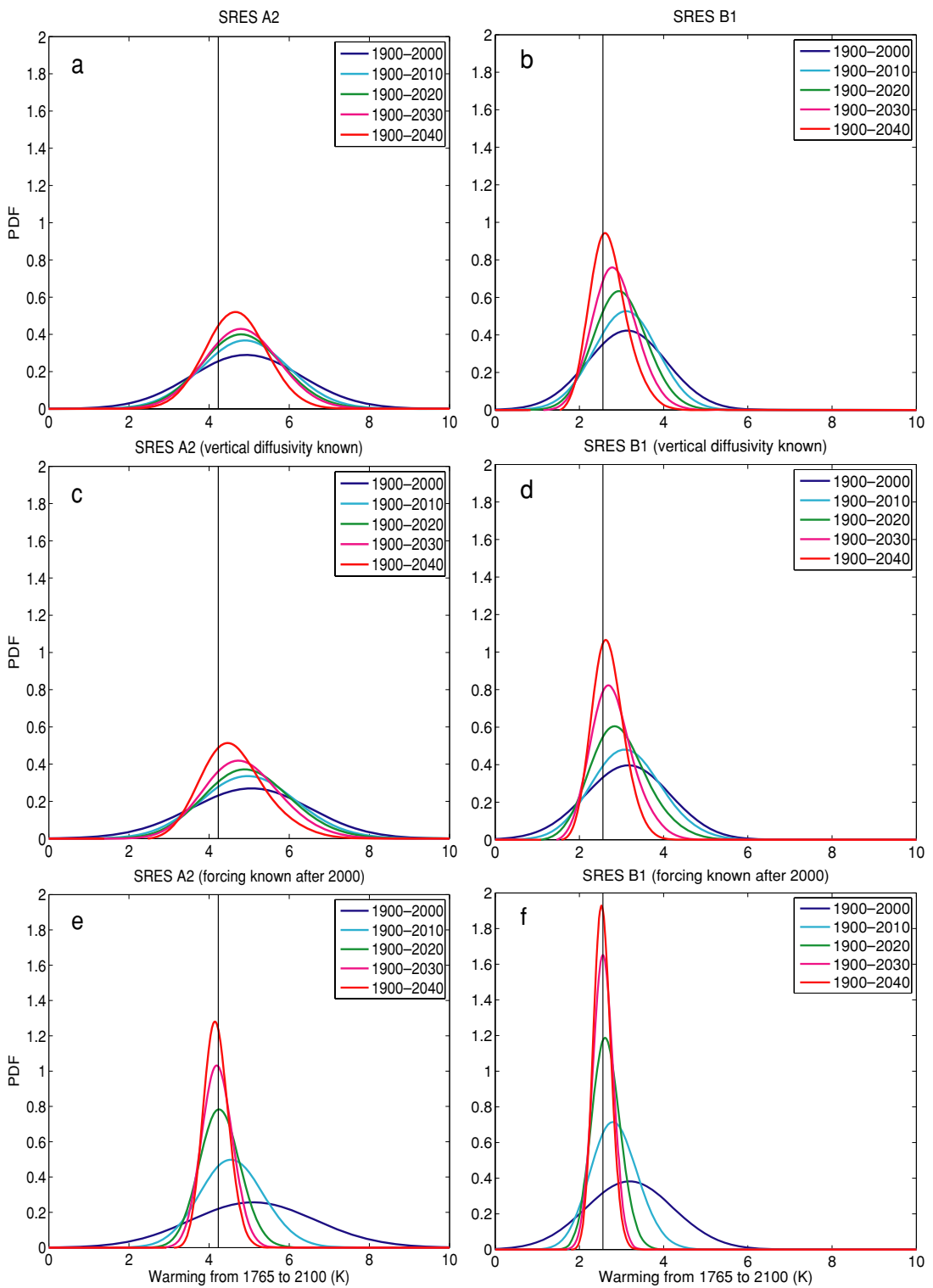

Fig. 4 Projected probability density functions (PDFs) for warming from 1765 to 2100 after the removal of climate sensitivity, ocean vertical diffusivity, and radiative forcing that do not match the 'true answer' (a substitute of observational records). The ranges of years in the upper right corner represent the periods of near surface air temperature record used to constrain the uncertain parameters. Note that the same period is used for the ocean heat content except that the starting year is 1955 instead of 1900 . Vertical lines represent true answers'. (a) SRES A2 scenario; (b) SRES B1 scenario; (c) same as in (a) but the ocean vertical diffusivity is assumed to be known; (d) same as in (b) but the ocean vertical diffusivity is assumed to be known; (e) same as in (a) but forcing is assumed to be known after year 2000; (f) same as in (b) but forcing is assumed to be known after year 2000. See text for further details 
scenarios SRES A2 and B1, respectively. PDFs narrow moderately with the use of longer observational records.

Figures $4 \mathrm{c}$ and $\mathrm{d}$ show the results subject to the assumption of perfect knowledge of ocean vertical diffusivity. The results exhibit few differences from Figures $4 a$ and $b$, implying that the impact of the uncertainty in ocean vertical diffusivity on temperature changes is small relative to other uncertainties. Figures $4 \mathrm{e}$ and $\mathrm{f}$ show the results when we assume perfect knowledge of radiative forcing after the year 2000. Here the results narrow dramatically the PDFs and thereby reduce the uncertainty range. This result points to the importance to focus efforts in quantifying the radiative forcing for the next decades. The figures also reveal that PDFs are biased from true values when the parameters are not well constrained by observations (cf. Figure 3).

Another possible avenue of future research is to increase the number of variables to further constrain uncertainty parameters. For example recent observational studies (Curry et al. 2003) showed that the anthropogenic signal is evident in the salinity field in the Atlantic Ocean during the past four decades. This suggests that the salinity field could serve as a potential constraint.

Here the focus was on estimating the uncertainty of climate projections. Next, we continue to address probabilistic methods and introduce quantitative statistical measures of forecast uncertainty, with a specific focus on the interface to operational application and the end-user perspective. This will be exemplified on the seasonal time-scale.

\section{Seasonal climate prediction}

\subsection{The rationale}

A major addition to the forecasting repertoire of weather services in recent years has been the development of operational techniques for seasonal climate predictions. It is argued that sustained large-scale surface (ocean and land-surface) forcing can exert a coherent and conceivably predictable atmospheric response on seasonal time-scales. Indeed the atmosphere itself exhibits coherent large-scale climate variations on this time-scale. Likewise it has been suggested that well-recognised atmospheric flow phenomena or features that are confined to specific regions/layers but that are sustained on quasi-seasonal time-scales can influence the seasonal patterns in the far-field. Two possible examples are the equatorially-based MaddenJulian Oscillation and the stratospheric polar annular oscillation.

Seasonal forecasts are derived using either statistical or dynamical models or a combination (for an overview see Goddard et al. 2003). In practice elements of the statistical and dynamical approaches are combined in a seasonal forecasting system (e.g., Palmer et al. 2005). For example a serial approach utilises a statistical model to generate oceanic boundary conditions for the atmospheric dynamical model (Colman and Davey 2003). Likewise the output of dynamical models can be subject to statistical post-processing to compensate for model drift or to counter known limitations such as resolution. Such a model calibration requires an adequate number of forecasts performed from initial states in the past ("hindcasts"). Most dynamical models or hybrid forecasting systems based upon a mix of statistical and dynamical ingredients exhibit a low signal-to-noise ratio. ${ }^{4}$ Hence the desire to derive estimates of forecast uncertainty in the probabilistic framework (Palmer 1993).

\footnotetext{
${ }^{4}$ Ratio of the variability related to external forcing and the unpredictable part of internal variability. 


\subsection{Ensemble prediction and multi-model approach}

One approach to this end is to perform multiple integrations with a specific dynamical model (cf. Section 2.4). One such example is the ECMWF Seasonal Forecast System 2 (Anderson et al. 2003b). It comprises a state-of-the-art coupled atmosphere-ocean model with the resolution of the atmospheric component being higher than standard GCMs and lower than that of the ECMWF's daily weather forecasting configuration. It produces 40 ensemble members, and runs operationally on a monthly basis with hindcasts available from 1987 onward.

Figure 5 shows the results from a typical seasonal ensemble forecast. Each line represents the predicted daily temperature anomaly for the individual members. Clearly care is required in the interpretation of such forecasts, noting that the ensemble mean does not encapsulate all useful information. It is evident that in this particular example there is a very low signal-tonoise ratio throughout, indicating a ly less-predictable situation. Note that the signal-to-noiseratio depends on the averaging of the data and would be different for monthly and seasonal means. Naively it might be expected that the spread of the members would increase with integration time. Here, however the spread does not increase steadily, reflecting a temporally varying predictability.

Another approach to garner more information for the post-processing statistics is to incorporate data from many different models. In effect such a multi-model prediction system (Fraedrich and Leslie 1987; Pavan and Doblas-Reyes 2000; Kharin and Zwiers 2003) can shed light on the uncertainties due to model formulations. This additional step leads to the concept of multi-model ensemble prediction systems (Harrison et al. 1995; Palmer and Shukla 2000; Shukla et al. 2000) that co-consider model-based and initial data uncertainties. Improvement in the performance using such a multi-model ensemble formulation has been shown for seasonal forecasts (Doblas-Reyes et al. 2000; Graham et al. 2000; Palmer et al.

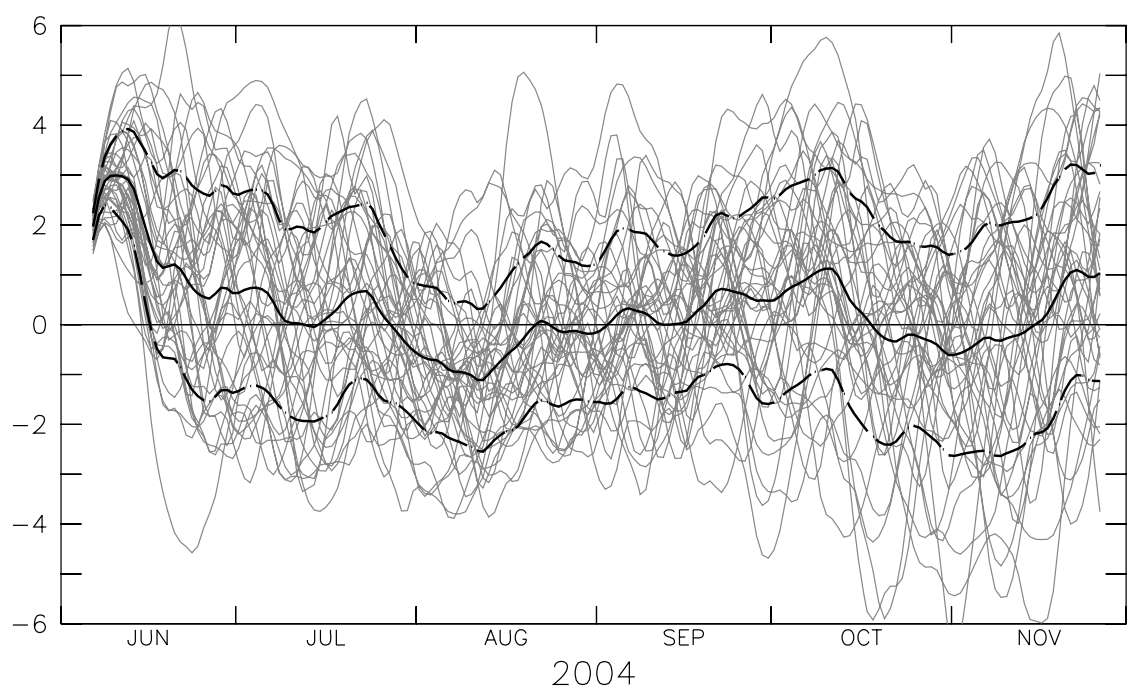

Fig. 5 Forecast initialized at 1 June 2004 for a point in NW-USA for the $2 \mathrm{~m}$ temperature. Shown are all 40 individual members (grey), the ensemble mean (solid line) with $+/-$ standard deviation (dashed) as anomaly versus the 1987 till 2001 model climatology. The forecast is based on the operational ECMWF seasonal forecast system 2 . The daily values are smoothed using a 14 day running average 
2004). However the relative merit of using a larger ensemble with a single model versus an ensemble derived from different (possibly inferior) models remains an open issue (Hagedorn et al. 2005; Doblas-Reyes et al. 2005). In this parallel approach, the forecasts of (ideally) independent sources and models are directly combined, e.g. as linear combination (Barnston et al. 1999b; Coelho et al. 2004) The technique of weighting the forecast models depending on their past performance (Thompson 1977) is still controversial since it is difficult to measure the model quality in its full phase space (Pavan and Doblas-Reyes 2000).

\subsection{Forecast verification and skill scores}

The difficulty of dealing with probabilistic forecasts is evident from inspection of Figure 5: How can such a noisy ensemble be quantitatively compared with a single observation? This illustrates the challenge in designing suitable verification procedures, and there are a range of measures (scores) for probabilistic forecast quality, i.e. the error relative to the corresponding observation.

Examples are Brier Scores (BS) or the Relative Operating Characteristics (for details see Swets 1973; Wilks 1995). These scores apply to forecasts for a specific kind of event (e.g. the probability that the temperature exceeds a certain threshold value), and are therefore termed dichotomous scores. Other more general scores are multi-categorical and provide both a measure of the shape as well as the central tendency of the whole probability density function (PDF), e.g. the probabilities that the temperature exceeds a range of different threshold values. One example is the ranked probability score (RPS) (Epstein 1969; Murphy 1969, 1971). It is an extension of the BS to multiple probabilistic categories. The RPS is usually calculated in probability space and not in physical space. For example, the threshold value for the RPS must not necessarily be a physical value but could also be defined relative to its statistical recurrence time in the past (i.e. quantile).

The comparison of the forecast performance with a reference forecast is measured by the skill score $(S S)$. Formally the skill score describes the benefit of a forecast score $S$ over the reference forecast score $S_{\text {ref }}$ relative to a perfect forecast score $S_{\text {perf }}(=0)$, i.e.

$$
S S=\frac{S-S_{\text {ref }}}{S_{\text {perf }}-S_{\text {ref }}}=1-\frac{S}{S_{\text {ref }}}
$$

As a reference forecast, usually a climatological, persistence or random forecast is employed. A positive skill score indicates an improvement with respect to the reference forecast, a negative skill a degradation.

A particular problem of systems with small ensemble size is that a comparison between the scores suffers from different discretization of the forecast and reference forecast probabilities. This leads to a negative bias of the expected skill score for systems with small ensemble size, commonly referred to as the equitability problem (e.g., Mason 2004). For the examples presented here (Sections 4.4 and 4.5) the skill score is evaluated by a newly defined modification which is referred to as debiased version of the standard RPSS (RPSS ${ }_{D}$, Müller et al. 2005a). The proposed modification involves the re-sampling of the reference forecast. For forecasts with no skill, the RPSS $_{D}$ gives values of zero even for systems with small ensemble sizes.

\subsection{Potential predictability on seasonal time scales}

In this sub-section we illustrate some of the points made above in the context of two particular settings. The first is the observationally-based forecast approach (FA). Here we deploy it in Springer 
the context of the ECMWF ERA-40 reanalysis data. The data set forms both the (quasi-) observations and defines the climatological distribution used as "reference" forecast. The second is the perfect model approach (PMA). In this setting the reference forecast is based on all single predicted ensemble members of the model climatology, and each single ensemble member is treated once as observation. In effect the PMA estimates the potential predictability of the system. It is independent of the real world observations and assumes that the model fully represents the climate system. By construction it exhibits no systematic model drifts, and provides a measure of mean shift and signal-to-noise ratio between the actual forecast and the model climatology.

For many applications, station-based forecasts are needed. As an approximation the forecast skill $\left(\mathrm{RPSS}_{D}\right)$ of the $2 \mathrm{~m}$ mean temperature is examined from a grid-point perspective. Figure 6 shows an example of the potential seasonal predictability of the operational ECMWF seasonal forecast system 2 for the period 1987-2002. In the FA (Figure 6a) high skill scores are found over the oceans, in particular over the tropics. Highest values are located in the El Niño region in the eastern tropical Pacific, whereas the western Pacific, the Indian Ocean and the tropical Atlantic show somewhat lower, but mostly significant positive skill. The heterogeneous patterns in the region of Indonesia are mostly due to the differences between the land-sea masks of the forecast model and the verification data set (ERA40). In the extratropics, the Pacific basin exhibits wide regions of significant skill. For the Atlantic basin, the

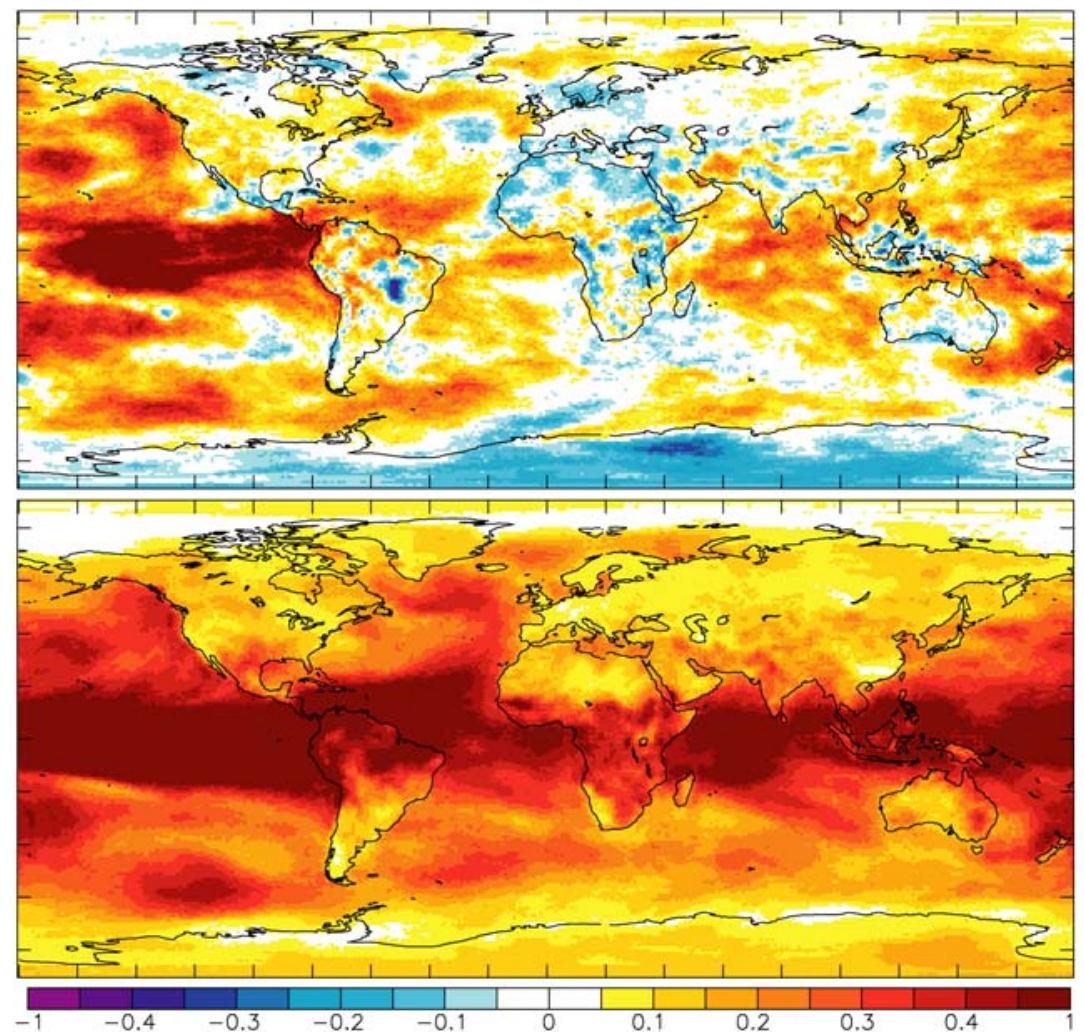

Fig. 6 The RPSS ${ }_{D}$ of the 3-monthly mean $2 \mathrm{~m}$ temperature with lead time of 1 month from 1987 till 2002 for the ECMWF seasonal forecast system 2. Shown are (a) the FA and (b) the PMA for all starting months 
values are closer to zero. Relevant for Europe, there is a band-like structure of a weak positive signal across the northern Atlantic reaching from Newfoundland to the Bay of Biscay. Over land, the skills are lower throughout. Highest values are found over Northern America, and along the Pacific coast of Asia. Most other continents, in particular Europe, are associated with negative or non-significant values.

The potential predictability estimated by the PMA supports these findings (Figure 6b). The tropical oceans feature high potential predictability. In the extratropics, the oceans show reduced but still significant positive values. Over land, the PMA implies a higher predictability in the tropics than extratropics (e.g. over Africa and Southern America). A comparison to the FA shows, that this potential is not realised in the actual forecast skill. A better agreement between PMA and FA is found in the extratropics with very limited, but significant, skill values. In particular over the European region the skill scores are in the order of less then $10 \%$, both for PMA and FA.

\subsection{Forecasting climate indices (ENSO and NAO)}

Accurate extended-range predictions of regional and global climate indices are highly desirable in the context of impact research and applications. Here we discuss and compare the forecast skills for the ENSO and NAO index.

Coupled atmosphere-ocean models as well as statistical models yield a significant positive level of forecast skill for ENSO up to a lead time of 12 months (for a review see Latif et al. 1998). The predictions depend critically on the phase of the ENSO (Fedorov 2002; Vitart et al. 2003; McPhaden 2004). In a comparative study of the forecast for the 1997/98 El Niño, Landsea and Knaff (2000) examined 12 deterministic statistical and dynamical models and found no skill beyond persistence on seasonal to inter-annual time scales for any model. More generally, van Oldenborgh et al. (2003) compared the ECMWF seasonal forecast system 1 and 2 (Anderson et al. 2003b) against a statistical and a persistence model of the form of Knaff and Landsea (1997) for the full period 1987-2001. In terms of skill, the statistical methods perform similar to the dynamical models in the winter months. However, in the summer months the skill scores of the statistical models are strongly reduced ("spring barrier"). Among all models, the lowest skill score is achieved by the persistence model in the summer months.

For the NAO, operational statistical and more recently dynamical forecasting systems suggest only moderate skill. The statistical properties of the time series enables statistical forecasts based directly on the time series (Stephenson et al. 2000). Other efforts have focused on the role of the Atlantic SST (Czaja and Frankignoul 1999, 2002; Peng et al. 2003), Eurasian snow cover (Cohen and Entekhabi 1999) and more recently the lower stratosphere (Baldwin and Dunkerton 2001; Baldwin et al. 2003). Recent modeling studies (Rodwell et al. 1999; Rodwell and Folland 2002) and statistical approaches (Saunders and Qian 2002) provide enhanced forecast skill with preceding summer/autumn SST. However, some authors explain the skill as a statistical artefact (Bretherton and Battisti 2000). Several studies investigate dynamical systems on the skill of NAO predictions (Doblas-Reyes et al. 2003; Müller et al. $2005 b$ ) and find very limited, but positive, skill values. Other large-scale variability patterns in the Euro-Atlantic sectors exhibit higher predictability, probably due to a more direct ocean forcing (Pavan et al. 2000a,b).

As an illustration, the skill for ENSO and NAO forecasts is calculated for the ECMWF seasonal forecasts system 2 (Figure 7). For the NAO, the skill scores are much lower than for the ENSO forecasts, with values of around $25 \%$ for the FA and much lower (8\%) for PMA. Both values are statistically significant as derived using a Monte Carlo approach. This 
Fig. 7 The RPSS $_{D}$ of (a) ENSO and (b) NAO index for winter (DJF) averages from 1987 till 2001 for the ECMWF seasonal forecast system 2 started at November 1 st. The verification is undertaken in the FA (light grey) and the PMA (black). The horizontal red lines denote the statistical significance level of $95 \%$
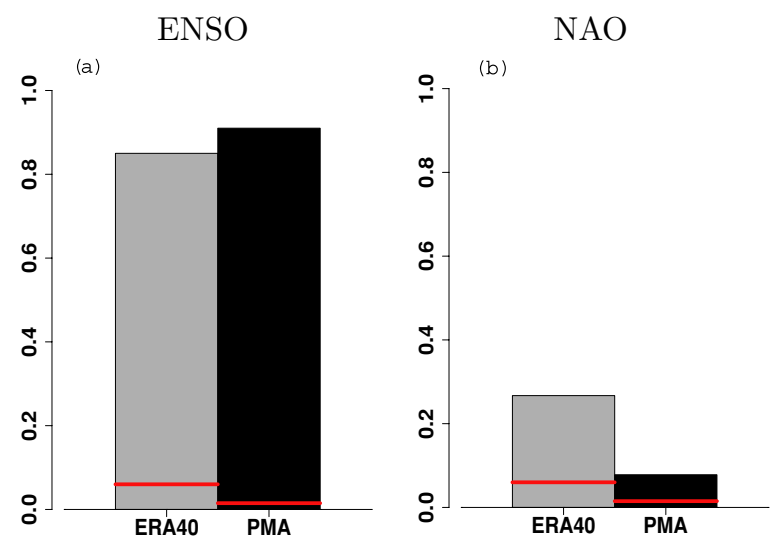

indicates that the potential predictability of this climate pattern is lower than the actually achieved skill over this period. Indeed, skill scores of this magnitude are very sensitive to the sample size and the NAO skill mainly originates from a few well-predicted events (DoblasReyes et al. 2003; Müller et al. 2005b). The limited number of available hindcasts for the operational ECMWF system 2 (15 years) is a major constraint for the verification.

The intra-seasonal dynamics of the above patterns of climate variability is at the heart of the following Section 5.

\section{Patterns of intra-seasonal variability and weather regimes}

\subsection{The rationale}

The regional impact of climate change is communicated through the leading modes of climate variability. To assess their behaviour under future climate change and to quantify the reliability of climate projections it is necessary to identify the dynamical and physical mechanisms that underly climate variability (Sutton 2005).

As indicated in Section 2.1, weather regimes such as atmospheric blocking, can have a significant impact on the patterns of inter-annual variability. This is supported by their large persistence of $\sim 10$ days; their spatial extent $\left(\mathcal{O}\left(10^{6}\right) \mathrm{km}^{2}\right)$; and their significant disturbance to the ambient climatic conditions. In effect blocking systems are associated with a reduction of the in-situ zonal wind, and a deflection of transient cyclonic systems away from their customary tracks with an accompanying marked redistribution of precipitation (Rex 1950a, b, Trigo et al. 2004). Hence the correct prediction of intra-annual and intra-seasonal variability and the associated uncertainty hinges to some extent on the predictability of the blocking phenomenon. The processes involved in blocking formation are complex and occur on a range of scales (see later), and their correct prediction, particularly their onset and breakdown remains difficult (Anderson 1993; D'Andrea et al. 1998; Oortwijn 1998).

It is therefore instructive: to consider the relation between blocking and modes of climate variability; to explore the cause-and-effect relationship between blocking and regional climate patterns; and to review some of the notions on the underlying dynamics of blocking, that might be crucial for the correct representation of blocking in models. 


\subsection{Blocking occurrence and climate variability patterns}

Climatologically for the Northern Hemisphere, the main centers of blocking activity are found over the oceanic basins with a secondary peak over Eurasia (Sausen et al. 1995; Lupo and Smith 1995; Wiedenmann et al. 2002; Schwierz et al. 2004). Some significant correlations have been noted between blocking frequency and large-scale patterns of climate variability. For example in the Pacific, the occurrence of intra-seasonal variations has been associated with tropical SST anomalies with enhanced blocking occurring during the La Niña phases (Wiedenmann et al. 2002), and it is further speculated that this might be reflected in the PNA pattern. However, other studies associate the intra-seasonal PNA variations to the MaddenJulian Oscillation (MJO), while ENSO seems more closely linked to higher order patterns of variability (Karoly et al. 1989; Frederiksen and Zheng 2004). In the Atlantic, the negative NAO phase is correlated with blocking occurrence in the west and central North Atlantic (Shabbar et al. 2001), while the positive NAO phase is associated with blocking over the Western European and Scandinavian region (Scherrer et al. 2006). The opposing phases of the higher modes of variability in the Atlantic region (EOF2-4, together accounting for $\sim 42 \%$ of variability) are even more clearly separating specific regions of European blocking occurrence (Scherrer et al. 2006). Interestingly the phase-separated blocking regions are significantly correlated in all 4 EOFs, for the daily as well as for the seasonal NAO-index. This indicates that a large amount of inter-annual variability of the Euro-Atlantic region results from intra-seasonal processes (Zheng and Frederiksen 2004; Frederiksen and Zheng 2004), where also tropical phenomena (such as the MJO) may play a role.

\subsection{Temporal relationship between NAO and euro-atlantic blocking}

The statistical correlations between NAO and Euro-Atlantic blocking, even though significant, do not point directly to a cause-and-effect relationship. This requires a more dynamically-based approach. One possibility is to investigate the evolution of the blocking system in relation to the contemporaneous strength of a variability pattern. To this end consider the Atlantic region and the relationship of blocking with the NAO pattern.

Individual winter blocks with a minimum life-time of 5 days are identified with the ERA40 data set (1958-2002), their location logged on a 6-hourly basis and their track determined from onset to breakdown (cf. Schwierz et al. 2004). Each block located entirely within the Euro-Atlantic region $\left[90^{\circ} \mathrm{W}: 50^{\circ} \mathrm{E}\right]$ is recorded and this yields a total of 178 cases. Likewise a similar procedure is followed for blocks located in the Pacific region $\left[110^{\circ} \mathrm{E}: 110^{\circ} \mathrm{W}\right]$, and there are 211 cases in this category. With this data set it is possible to record the temporal evolution of mean-flow climate parameters (such as the NAO index) during the life cycle of the block.

Figure 8 shows the NAO index value throughout the life time of the blocking systems. (Note individual blocking systems differ in their duration, and hence the index is plotted against the relative blocking life time ranging from $0-100 \%$ ). The NAO indices at a particular step in the life cycle are then averaged over (i) all blocks in the Euro-Atlantic region, and (ii) blocks in the Pacific, and a distinction is made between classes of blocks lasting less/more than 10 days.

The figure reveals several interesting features. In the Euro-Atlantic sector long-lasting blockings are clearly associated with the negative NAO phase, cf. the spatial distributions shown in Croci-Maspoli et al. (2006), whereas the blocks in the 5-10 day category exhibit no such dependence. (For the Pacific sector there is no clearly detectable relationship of blocks with the NAO index.) A particularly significant feature in the Euro-Atlantic sector 


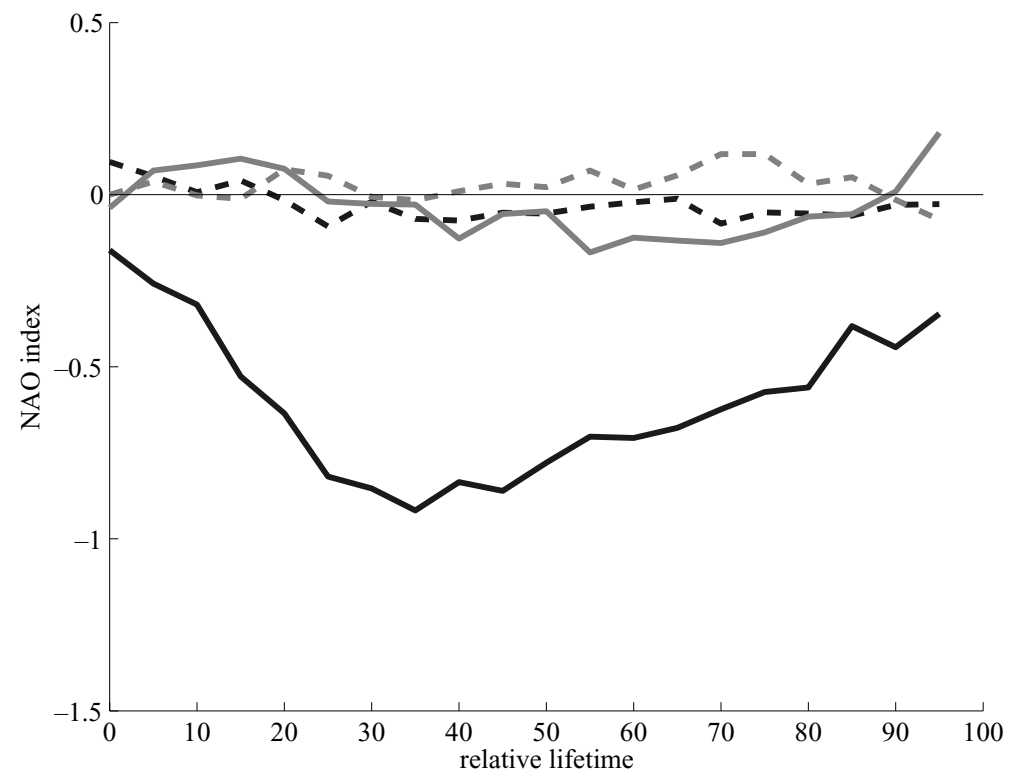

Fig. 8 Development of the median NAO index (daily data, in units of the standard deviation) during the blocking life cycles (relative life time of block in \%) for winter (DJF) and for blocks with 5 day minimum life time, for the Euro-Atlantic region (black) and the Pacific region (grey). Blocking are grouped by their life-times between 5-10 days (dashed) and life-times greater than 10 days (solid). Refer to text for further details. The index is that of the Climate Prediction Center CPC http: / www . cpc.ncep.noaa.gov

relates to the relative temporal development of the NAO and long-lasting blocks ( $>10$ days). In effect the NAO index decreases (i.e. strengthens markedly) during the life cycle of the block with the block starting to form in a near neutral NAO environment. Typically as the blocks develop, the mean value of their contemporaneous NAO index decreases and reaches its minimum at $\sim 35 \%$ of the blocking life-time. Subsequently as the block decays, the NAO index also increases back toward a more neutral state. In essence these results indicate a striking temporal relationship between the evolution of a synoptic-scale block that appears to lead the progression of the large-scale flow into a significant NAO negative phase in the Atlantic region.

\subsection{Dynamics of blocking, physical processes}

To address the question to what degree the phenomenon of blocking can be represented in climate models, it is instructive to consider the dynamical processes and interactions central to the formation, maintenance and breakdown of blocks. In particular current blocking theories provide a hint of the spatial resolution and nature of the model formulation necessary to simulate this intra-seasonal climate phenomenon.

The characteristic shift from a more zonal flow regime to the blocked flow state has been linked to the existence of multiple stable flow equilibria and resonance (Charney and DeVore 1979; Legras and Ghil 1985). In effect multiple equilibria can be viewed as attractors "fixed points" - in phase space providing a predilection for certain flow regimes with specific implications for predictability (cf. the studies using Lorenz-type models) (Yamane and Yoden 1997; Corti and Palmer 1997; Palmer 1999). Also it has been argued that the influence of 
topography upon the zonal mean flows can destabilise the flow and lead the system to oscillate from one attractor to another (Haines and Hannachi 1995).

A related group of studies link blocks to the amplification of stationary planetary-scale waves (Cerlini et al. 1999; Liu 1994; Da Silva and Lindzen 1993; Hansen and Sutera 1993; Nigam and Lindzen 1989), and the importance of non-linear interactions with large-scale travelling waves has been stressed (Egger 1978). For blocking, the constructive interference of land-sea contrast (thermal forcing) and topographic forcing seems to be crucial (Ji and Tibaldi 1983; Tung and Lindzen 1979; Egger 1978), and no long-lasting events ( $>6$ days) were possible without mountains in numerical sensitivity experiments (Mullen 1989a). From mountain torque and angular momentum analyses, Lott et al. (2004a; b) also concluded, that the jet streams' interactions with large-scale topography play a key-role for hemispheric and regional variability on the 20-30-day time-scale.

There is evidence that certain large-scale mechanisms precondition the atmosphere so as to favour blocking formation. Da Silva and Lindzen (1993) and Nigam and Lindzen (1989) showed that the stationary wave amplitude is sensitive to small shifts in the subtropical jet and the sharpness of the jet. Preconditioning by teleconnection patterns involves a tropical diabatic vorticity anomaly with a subsequent global-scale Rossby-wave train into the extratropics (Hoskins and Karoly 1981; Simmons et al. 1983; Hoskins and Sardeshmukh 1987).

A more local view of blocking maintenance is the so-called eddy-straining hypothesis that relates to the modification of the mean flow by the eddies (Berggren et al. 1949; Shutts 1983; Mullen 1987; Vautard et al. 1988). More recent studies by Tsou and Smith (1990), and Lupo and Smith (1995) and others confirm the feedback from eddies to the mean flow in the case of blocking events.

It has been shown, that moist cloud-diabatic processes induced by transient synoptic systems and orographic forcing can act to maintain blocking anomalies Schwierz (2001). Transient disturbances are also believed to play a crucial role in the onset and breakdown of the blocking anomalies. Deep upstream cyclogenesis appears to trigger Atlantic blocking. Ji and Tibaldi (1983), Crum and Stevens (1988), and Lupo and Smith (1995) found a positive correlation between the intensity of blocking anticyclones and the intensity of the precursor cyclone development.

It is evident from the above that many components of the climate system potentially play a role in the dynamics of blocking. From a predictability perspective, elements such as topography, cyclones, moist processes, tropical and stratospheric forcings need to be resolved and represented appropriately.

\subsection{Predictability of blocking and climate patterns}

Difficulties in forecasting block occurrence might well relate to the intrinsic predictability of the associated climate regime. Studies have been undertaken using a range of approaches from experiments with state-of-the-art NWP models to probabilistic methods, such as (i) seasonal ensemble hindcasts of Euro-Atlantic wintertime variability (Pavan et al. 2000b), (ii) assessment of predictability of blocking with ensemble methods (Frederiksen et al. 2004; Mauritsen and Källén 2004; Pelly and Hoskins 2003; Watson and Colucci 2002), (iii) the multi-model approach (Pavan and Doblas-Reyes 2000; Doblas-Reyes et al. 2003) (cf. also Section 4.2), and also (iv) climate simulations and GCM intercomparison projects (Sausen et al. 1995; Tibaldi et al. 1997; D’Andrea et al. 1998; Doblas-Reyes et al. 1998).

Some standard model deficiencies can impact on the prediction of blocks and intraseasonal variability. For example in GCMs these include: an excessive zonality of jet streams; greater than normal storm track activity and undersimulation of low-frequency planetary and Springer 
stationary waves. For the prediction of blocks themselves it has been noted that there is: $-\mathrm{a}$ general tendency to underestimate blocking activity (frequency), particularly for extended forecast times Jung (2005); -a lack of long-lived blocks (D'Andrea et al. 1998); -a tendency of Atlantic blocking to be shifted east, since transients penetrate too far east and south as the jet stream becomes too zonal (Doblas-Reyes et al. 1998) (Pacific blocking predictions do not show this tendency). Moreover forecast model errors differ significantly in the skill in representing Pacific and Atlantic blocks (Tibaldi et al. 1994), and indeed the skill of the (ECMWF) seasonal model prediction is higher in the Pacific than in the Atlantic (Pavan et al. 2000a). This in turn might betoken the fact that different processes for blocking formation prevail for the two main $\mathrm{NH}$ blocking regions.

A regime-dependent component has been found in forecast error fields (Molteni and Tibaldi 1990), and the systematic model errors of 500-hPa geopotential height are related to the inability to predict blocking (Mauritsen and Källén 2004). This has ramifications for quantifying forecast uncertainty, and in particular the difficulties in correctly predicting the onset and break-down of blocking periods have profound implications. In the medium range, major forecast failures are associated with regime transitions, that affect the statistical properties of the errors (Trevisan et al. 2001).

For long-range or seasonal prediction, the presumed linkage of sea-surface temperature (SST) anomalies to patterns of climate variability and blocking is noteworthy and relates to the paradigm of preconditioning the atmosphere towards specific regimes of variability. Earlier studies hinted at the impact of Pacific SST anomalies on blocking location (Mullen 1989b). In the North Pacific, low-frequency (blocking) variability is enhanced during La Niña winters and hence potential predictability during El Niño winters is increased (Chen and van den Dool 1999). Using GCM experiments, Cassou et al. (2004) and Mathieu et al. (2004) find that tropical and extra-tropical Atlantic SST anomalies can significantly affect the excitation of North Atlantic climate regimes such as the NAO and blocking. The influence of ENSO-modulated SST anomalies on Euro-Atlantic blocking can be limited by the model's ability to correctly represent planetary wave propagation from the Pacific into the Atlantic (Pavan et al. 2000b).

\subsection{Further comments and challenges}

In this section we have emphasised the issue of predictability and illustrated the challenge of climate variability prediction from a process-based standpoint. The range and interaction of processes and the need to represent them sufficiently accurately is a major difficulty for prediction. Here this was pinpointed in the context of the need for a better fundamental understanding of the synoptic processes underlying the onset, maintenance and breakdown of blocks (sic. weather regimes) and their non-linear two-way interaction with the pattern of climate-scale variability.

For example the co-development of an individual blocking event and a negative NAO phase has been shown to be linked to the life time of the block. The implication is that a model should adequately represent the processes relevant for blocking (wave interactions, diabatic heating, interactions with the ocean or stratosphere).

Sensitivity studies with climate models of parameters such as resolution, physical parametrisation, moisture content, surface schemes, representation of ocean and tropical processes might help to investigate the link between predictability of climate and weather regimes. And indeed there are indications that some of the model errors for blocking can be alleviated by increased resolution (Doblas-Reyes et al. 1998) and improvements in the physical parametrisation (Molteni and Tibaldi 1990). 


\section{Final remarks}

A major difficulty in predictions and the assessment of uncertainty is the determination and separation of influencing factors on climate variability and change. These comprise a forced component (GHGs), internal sources (such as QBO, NAO, PNA, ENSO, feedback with eddies), residual weather "noise" and their non-linear interactions.

It has been argued here that a hierarchy of models is a powerful approach to estimate and assess the uncertainty. Dynamical models have been combined with models of reduced complexity, and with statistical models. Beneficial for the assessment is an overlap between the model evaluations. For instance models used in NWP can be combined with GCMs for climate and seasonal time scales to determine the accurate representation of processes (Section 5). Such GCMs in connection with reduced-complexity and statistical models, which are often used in an ensemble mode, are efficient in the estimation of errors. In addition such an overlap can lend credence to the applicability of the less-detailed models (cf. Section 3). However, long-term projections - in particular when undertaken with statistical models - rely on assumptions such as stationarity and ergodicity which are not fulfilled for instance for dramatic changes in circulation patterns. (cf. Section 2). Climate models, especially with reduced complexity and relaxed non-linearity, will not necessarily foresee a major change in dominant circulation regimes (Smith 2002).

\subsection{Internal, natural, and regional variability}

Hence, the application of a model hierarchy is also beset with problems. In climate studies, the internal variability of the climate system sets a level of background noise to attempts to estimate or predict an external or anthropogenic signal (Manabe and Stouffer 1996; Stouffer et al. 2000). A prediction by a single climate simulation or any parameter estimation that uses observational records as a constraint is subject to the uncertainties due to this internal variability and stochastic uncertainties (Murphy et al. 2004). These uncertainties are expected to increase if one goes to regional scales.

It has been argued that the externally forced signal may be preferentially projected onto the existing large scale modes of variability inherent in the climate system by changing the probability distribution of weather regimes (Palmer 1998, 1999; Corti et al. 1999; Monahan et al. 2000). Considering the impact of these large scale modes of variability on regional climate (Hurrell 1995, 1996; Thompson and Wallace 2001) as well as on the THC (Latif et al. 2000; Delworth and Dixson 2000; Schmittner et al. 2000), the understanding of underlying mechanisms of internal variability is important for (i) the justification of the choice of a model of reduced complexity and (ii) the extension of uncertainty assessment toward regional scales. In addition, the spatial inhomogeneity of radiative forcing, e.g. by tropospheric aerosols, which is represented as a globally uniform radiative forcing in reduced complexity models, may have a non-negligible impact on regional-scale climate change.

\subsection{Reduced complexity models}

The potential utility of a reduced complexity models is enhanced if its response overlaps and replicates that of comprehensive model. An example of such an overlap is the projection of future changes in the thermohaline circulation (THC). The fate of the THC in a warming world has attracted considerable attention due to its significant global and regional impact. Stocker and Schmittner (1997) used a multi-basin, zonally-averaged ocean model coupled to a 1-D EBM and conducted a series of experiments with different boundary conditions. 
They found that the reduction of the THC depends on the rate of increase in GHG forcing. A similar result, albeit in a much smaller parameter space, was derived with a 3-D fully coupled GCM (Stouffer and Manabe 1999). The THC system is highly nonlinear, and hence a large number of ensemble members are necessary to obtain a robust picture. Indeed, many GCMs project quite different strengths of the future THC (as well as modern simulations). Knutti and Stocker (2002), using a similar model as Stocker and Schmittner (1997), conducted an ensemble of 100 simulations with different noise sequences which represent the atmospheric internal variability. For that particular model setting they showed that the predictability of THC is severely limited when the system approaches the instability threshold or bifurcation point.

\subsection{Structural uncertainty}

GCMs, albeit expensive, are believed to be better suited for the use in projections of future climate change. However, reduced complexity models are very useful to assess uncertainty with probabilistic representations and ensemble methods. It is also possible for those models to objectively optimise the model parameter values, and hence reduce the parametric uncertainties. For reduced complexity models to serve as GCM substitutes, it is desirable to direct more effort towards the structural uncertainties. It remains a challenge to assess how much uncertainty or error could be introduced by reducing the complexity of models. Of course, structural uncertainty does not only exist in reduced complexity models but also in GCMs. With regard to THC projections, for example, these are poor representation of western boundary currents, deep convection, and flow over shallow sills. It is hoped that these weaknesses in GCMs are continuously improved as our understanding on fundamental processes and computational power increase. A hierarchy of climate models is useful and necessary, but more studies, particularly in quantification of the structural uncertainty, are highly desirable.

\subsection{Operational application and challenges}

Seasonal climate forecasting has recently become operational at many weather centers around the globe. Such forecasts provide potentially useful information to support decision makers in the governmental and private sectors. Substantial effort is also undertaken to improve applications in other sectors such as agricultural or health sectors (Palmer et al. 2004). But many issues still need to be resolved. Assuming that the current models do adequately represent the key processes and interactions Figure 6 suggests that the potential predictability is high in tropical regions but rather small in the extra-tropical European region. From an application perspective the following issues seem to be particularly important. First the climate system itself needs to be potentially predictable in the region and for the quantity of interest. Second, the current forecast systems still suffer from not being fully reliable systems. This indicates that the way the spread of the ensemble system is generated needs to be improved. One approach to do so is the use of a multi-model system as described in Section 4.2. Finally, the climate models used need to be able to represent the relevant processes that control climate variability on seasonal time scales. An example is the development of blocking systems (cf. Section 5).

Increased understanding of processes acting at this interface between weather and climate is needed to bridge the gap between the time-scales. "Since they are the only patterns arising from intraseasonal variability that contribute significantly to the interannual variability of the seasonal-mean field, they are the major patterns that one should pay prime attention to 
in medium-range weather forecasting, in order to improve dynamical seasonal forecasts" (Zheng and Frederiksen 2004). Potential shortcomings of the current models in representing the salient physical mechanisms need to be identified. A combination of (i) data diagnosis, (ii) sensitivity studies on resolution, parametrisations, moisture fields, surface schemes, ocean and tropical representations, undertaken with a hierarchy of models, (iii) theoretical considerations and (iv) the application of probabilistic methods are instrumental in this purpose. Together with the necessity to integrate the various research efforts in the relevant fields.

Acknowledgements This paper is a contribution to the synthesis report of the Swiss NCCR Climate Programme, Phase 1 (2001-2004). MY and TFS are indebted to Fortunat Joos for kindly providing radiative forcing data and useful programmes, and would like to thank Neil Edwards for useful discussions and Dáithí Stone for helpful comments. CS and HCD acknowledge the assistance of Mischa Croci-Maspoli with the preparation of Figure 8. This study was supported by the Swiss NCCR Climate Programme.

\section{References}

Allen M (1999) Do-it-yourself climate prediction. Nature 401(6754):642

Allen M, Raper S, Mitchell J (2001) Uncertainty in the IPCC's third assessment report. Science 293(5529):430433

Allen MR, Stainforth DA (2002) Towards objective probabilistic climate forecasting. Nature 419(6903):228

Allen MR, Stott PA, Mitchell JFB, Schnur R, Delworth TL (2000) Quantifying the uncertainty in forecasts of anthropogenic climate Change. Nature 407(6804):617-620

Anderson JL (1993) The climatology of blocking in a numerical forecast model. J Climate 6(6):1041-1056

Anderson TL, Charlson RJ, Schwartz SE, Knutti R, Boucher O, Rodhe H, Heintzerberg J (2003a) Climate forcing by aerosols - a Hazy picture. Science 300(5622):1103-1104

Anderson DL, Stockdale T, Balmaseda M, Ferranti L, Vitard F, Doblas-Reyes FJ, Hagedorn R, Jung T, Vidard A, Troccoli A, Palmer TN (2003b) Comparison of the ECMWF seasonal forecast systems 1 and 2 , including the relative performance for the 1997/8 El Niño, vol. 404 of ECMWF Technical Memorandum. ECMWF, p. 93

Andronova NG, Schlesinger ME (2001) Objective estimation of the probability density function for climate sensitivity. J Geophys Res 106(D19):22605-22611

Annan JD, Hargreaves JC, Edwards NR, Marsh R (2005) Parameter estimation in an intermediate complexity earth system model using an ensemble Kalman filter. Ocean Model 8(1-2):135-154

Appenzeller C, Stocker F, Anklin M (1998) North Atlantic Oscillation dynamics recorded in Greenland Ice Cores. Science 282:446-449

Bader J, Latif M (2003) The impact of decadal-scale Indian Ocean sea surface temperature anomalies on Sahelian rainfall and the North Atlantic Oscillation. Geophys Res Let 30:1-4

Baldwin MP, Dunkerton TJ (2001) Stratospheric harbingers of anomalous weather regimes. Science 294(5542):581-584

Baldwin MP, Stephenson DB, Thompson DWJ, Dunkerton TJ, Charlton AJ, OíNeill A (2003) Stratospheric memory and skill of extended-range weather forecasts. Science 301:636-640

Barnston AG, Glantz MH, He YX (1999a) Predictive skill of statistical and dynamical climate models in SST forecasts during the 1997-1998 El Niño episode and the 1998 La Niña onset. Bull Am Meteor Soc 80(2):217-243

Barnston AG, Leetmaa A, Kousky VE, Livezey RE, O’Lenic E, Van den Dool H, Wagner AJ, Unger DA (1999b) NCEP Forecasts of the El Niño of 1997/1998 and its U.S. Impacts. Bull Am Meteor Soc 80(9):1829-1852

Berggren R, Bolin B, Rossby CG (1949) An aerological study of zonal motion, its perturbations and breakdown. Tellus 1:14-37

Bjerknes J (1964) Atlantic air-sea interaction. Adv Geophys 10:1-82

Bretherton CS, Battisti DS (2000) An interpretation of the results from atmospheric general circulation models forced by the time history of the observed sea surface temperature distribution. Geophys Res Let 27(6):767-770

Budyko MI (1969) Effect of solar radiation variations on climate of earth. Tellus 21(5):611-619

Buizza R, Miller M, Palmer TN (1999) Stochastic representation of model uncertainties in the ECMWF ensemble prediction system. Quart J Roy Meteor Soc 125(560):2887-2908 
Cassou C, Terray L, Hurrell JW, Deser C (2004) North Atlantic winter climate regimes: Spatial asymmetry, stationarity with time, and oceanic forcing. J Climate 17(5):1055-1068

Cerlini PB, Corti S, Tibaldi S (1999) An intercomparison between low-frequency variability indices. Tellus A 51(5):773-789

Charney JG, DeVore JG (1979) Multiple flow equilibria in the atmosphere and blocking. J Atmos Sci 36:12051216

Chen WY, van den Dool HM (1999) Significant change of extratropical natural variability and potential predictability associated with the El Nino/Southern Oscillation. Tellus A 51(5):790-802

Claussen M, Mysak LA, Weaver AJ, Crucifix M, Fichefet T, Loutre M-F, Weber SL, Alacamo J, Alexeev VA, Berger A, Calov R, Ganopolski A, Goosse H, Lohmann G, Lunkeit F, Mokhov II, Petoukhov V, Stone P, Wang Z (2002) Earth system models of intermediate complexity: Closing the gap in the spectrum of climate system models. Clim Dyn 18(7):579-586

Coelho CAS, Pezzulli S, Balmaseda M, Doblas-Reyes FJ, Stephenson DB (2004) Forecast calibration and combination: A simple bayesian approach for ENSO. J Clim 17:1504-1516

Cohen J, Entekhabi D (1999) Eurasian snow cover variability and northern hemisphere climate predictability. Geophys Res Let 26(3):345-348

Colman AW, Davey MK (2003) Statistical prediction of global sea-surface temperature anomalies. Int J Climatol 23(14):1677-1697

Corti S, Palmer T (1997) Sensitivity analysis of atmospheric low-frequency variability. Quart J Roy Meteor Soc 123(544):2425-244

Corti S, Molteni F, Palmer TN (1999) Signature of recent climate change in frequencies of natural atmospheric circulation regimes. Nature 398(6730):799-802

Covey C, AchuaRao KM, Cubasch U, Jones P, Lambert SJ, Mann ME, Phillips TJ, Taylor KE (2003) An overview of results from the coupled model intercomparison project. Global and Planetary Change 37:103133

Croci-Maspoli M, Schwierz C, Davies HC (2006) A multi-faceted climatology of atmospheric blocking and its recent linear trend. J Clim (in press)

Crum FA, Stevens DE (1988) A case study of atmospheric blocking using isentropic analysis. Mon Wea Rev 116(1):223-241

Cubasch U, Meehl GA, Boer GJ, Stouffer RJ, Dix M, Noda A, Senior CA, Raper S, Yap KS (2001) Projections of future climate change. In: Houghton JT, Ding Y, Griggs DJ, Noguer M, van der Linden PJ, Dai X, Maskell K, Johnson CA (eds) Climate change 2001: The scientific basis. Cambridge, UK and New York, NY, USA: Cambridge University Press, Chapt. 9, pp. 525-582. Contribution of Working Group I to the Third Assessment Report of the Intergovenmental Panel on Climate Change, p. 881

Curry R, Dickson B, Yashayaev I (2003) A change in the freshwater balance of the Atlantic Ocean over the past four decades. Nature 426(6968):826-829

Czaja A, Frankignoul C (1999) Influence of the North Atlantic SST on the atmospheric circulation. Geophys Res Let 26(19):2969-2972

Czaja A, Frankignoul C (2002) Observed impact of Atlantic SST anomalies on the North Atlantic Oscillation. J Clim 15(6):606-623

Da Silva AM, Lindzen RS (1993) The effect of concentrated PV gradients on stationary waves. J Atmos Sci 50(1):43-61

D’Andrea F, Tibaldi S, Blackburn M, Boer G, Déqué M, Dix MR, Dugas B, Ferranti L, Iwasaki T, Kitoh A, Pope V, Randall D, Roeckner E, Straus D, Stern W, van den Dool H, Williamson D (1998) Northern Hemisphere atmospheric blocking as simulated by 15 atmospheric general circulation models in the period 1979-1988. Clim Dyn 14(6):385-407

Delworth TL, Dixson KW (2000) Implications of recent trend in the Arctic/North Atlantic Oscillation for the North Atlantic thermohaline circulation. J Climate 13(21):3721-3727

Diaz HF, Markgraf V (2000) El Niño and the southern Oscillation: Multiscale variability and global and regional impacts. Cambridge University Press.

Doblas-Reyes FJ, Deque M, Piedelievre JP (2000) Multi-model spread and probabilistic seasonal forecasts in PROVOST. Quart J Roy Meteor Soc 126(567):2069-2087

Doblas-Reyes FJ, Déqué M, Valerbo F, Stephenson DB (1998) North Atlantic Wintertime intraseasonal variability and its sensitivity to GCM horizontal resolution. Tellus 50A:573-595

Doblas-Reyes FJ, Hagedorn R, Palmer TN (2005) The rationale behind the success of multi-model ensembles in seasonal forecasting - II. Calibration and combination. Tellus 57A:234-252

Doblas-Reyes FJ, Pavan V, Stephenson DB (2003) The skill of multi-model seasonal forecasts of the wintertime North Atlantic Oscillation. Clim Dyn 21(5-6):501-514

Edwards NR, Marsh R (2005) Uncertainties due to transport-parameter sensitivity in an efficient 3-d oceanclimate model. Clim Dyn 24(4):415-433 
Egger J (1978) Dynamics of blocking highs. J Atmos Sci 35(10):1788-1801

Ehrendorfer M (1997) Predicting the uncertainty of numerical weather forecasts: A review. Meteor Zeitschr 6:147-183

Epstein ES (1969) A scoring system for probability forecasts of ranked categories. J Appl Meteor 8:985-987

Fedorov AV (2002) The response of the coupled tropical ocean-atmosphere to westerly wind bursts. Quart J Roy Meteor Soc 128(579):1-23

Feldstein SB (2000) The timescale, power spectra and climate noise properties of teleconnection patterns. J Clim 13:4430-4440

Forest CE, Stone PH, Sokolov AP, Allen MR, Webster MD (2002) Quantifying uncertainties in climate system properties with the use of recent climate observations. Science 295(5552):113-117

Fraedrich K (1994) ENSO impact on Europe - a review. Tellus 46A:541-552

Fraedrich K, Leslie LM (1987) Combining predictive schemes in short-term forecasting. Mon Wea Rev 115(8):1640-1644

Frederiksen CS, Zheng X 2004 Variability of seasonal-mean fields arising from intraseasonal variability. Part 2, application to NH winter circulations. Clim Dyn 23(2):193-206

Frederiksen JS, Collier MA, Watkiins AB (2004) Ensemble prediction of blocking regime transitions. Tellus 56A(5):485-500

Gallée H, van Ypersele JP, Fichefet T, Tricot C, Berger A (1991) Simulation of the last glacial cycle by a coupled, sectorially averaged climate-ice sheet model 1. The climate model. J Geophys Res 96(D7):13139-13161

Gates WL, Boyle JS, Covey C, Dease CG, Doutriaux CM, Drach RS, Fiorino M, Gleckler PJ, Hnilo JJ, Marlais SM, Phillips TJ, Potter GL, Santer BD, Sperber KR, Taylor KE, Williams DN (1999) An overview of the results of the atmospheric model intercomparison project (AMIP I). Bull Am Meteorol Soc 80(1):2955

Gillett NP, Graf HF, Osborn TJ (2003) Climate Change and the North Atlantic Oscillation. In: Hurrell JW, Kushnir Y, Ottersen G, Visbeck M (eds) The North Atlantic Oscillation: Climate significance and environmental impact, Vol. 134 of geophysical monograph. Washington, DC, USA: American Geophysical Union, pp 193-209

Goddard L, Barnston AG, Mason SJ (2003) Evaluation of the IRI's "net assessment" seasonal climate forecasts 1997-2001. Bull Am Meteor Soc 84(12):1761-1781

Graham RJ, Evans ADL, Mylne KR, Harrison MSJ, Robertson KB (2000) An assessment of seasonal predictability using atmospheric general circulation models. Quart J Roy Meteor Soc 126(567):2211-2240

Greatbatch RJ, Lu J, Peterson A (2004) Nonstationary impact of ENSO on Euro-Atlantic winter climate. Geophys Res Let 31, doi:10.1029/2003GL018542

Grübler A, Nakicenovic N (2001) Identifying dangers in an uncertain climate. Nature 412(6842):15

Hagedorn R, Doblas-Reyes FJ, Palmer TN (2005) The rationale behind the success of multi-model ensembles in seasonal forecasting. - I. Basic concept. Tellus 57A:219-233

Haines K, Hannachi A (1995) Weather regimes in the Pacific from a GCM. J Atmos Sci 52(13):2444-2462

Hansen AR, Sutera A (1993) A comparison between planetary-wave flow regimes and blocking. Tellus 45A(4):281-288

Hargreaves JC, Annan JD, Edwards NR, Marsh R (2004) An efficient climate forecasting method using an intermediate complexity earth system model and the ensemble Kalman filter. Clim Dyn 23(7-8):745-760

Harrison MSJ, Palmer TN, Richardson TN, Buizza DS, Petroliagis T (1995) Joint ensembles from the UKMO and ECMWF models. In: ECMWF seminar proceedings, predictability, Vol. 2. pp 61-120

Hasselmann K (1976) Stochastic climate models: 1. Theory. Tellus 28(6):473-485

Haywood J, Boucher O (2000) Estimates of the direct and indirect radiative forcing due to tropospheric aerosols: A review. Rev Geophys 38(4):513-543

Hoerling MP, Hurrell J, Xu TY (2001) Tropical origins for recent North Atlantic climate change. Science 292:90-92

Hogg AM, Dewar WK, Killworth PD, Blundell JR (2003) A quasi-geostrophic coupled model (Q-GCM). Mon Wea Rev 131(10):2261-2278

Hoskins BJ, Karoly DJ (1981) The steady linear response of a spherical atmosphere to thermal and orographic forcing. J Atmos Sci 38:1179-1196

Hoskins BJ, Sardeshmukh PD (1987) A diagnostic study of the dynamics of the Northern- Hemisphere winter of 1985-1986. Quart J Roy Meteor Soc 113(477):759-778

Hurrell JW (1995) Decadal trends in the North Atlantic Oscillation: Regional temperatures and precipitation. Science 269(5224):676-679

Hurrell JW (1996) Influence of variations in extratropical wintertime teleconnections on Northern Hemisphere temperature. Geophys Res Lett 23(6):665-668

Hurrell J, Kushnir Y, Ottersen G, Visbeck M (2003) An overview of the North Atlantic Oscillation. In: Hurrell JW, Ottersen G, Visbeck M (eds) The North Atlantic Oscillation, pp 1-36 
Hurrell J, Hoerling MP, Phillips AS, Xu T (2004) Twentieth century North Atlantic climate change. Part I: assessing determinism. Clim Dyn 23:371-389

IPCC (1990) Climate change: The IPCC scientific assessment. Cambridge, UK: Cambridge University Press. Report Prepared for IPCC by Working Group 1, p 365

IPCC (1996) Climate change 1995: The science of climate change. Cambridge, UK: Cambridge University Press. Contribution of Working Group I to the Second Assessment Report of the Intergovernmental Panel on Climate Change, p 572

IPCC (2001) Climate change 2001: The scientific basis. Cambridge, UK and New York, NY, USA: Cambridge University Press. Contribution of Working Group I to the Third Assessment Report of the Intergovenmental Panel on Climate Change, $\mathrm{p} 881$

Ji LR, Tibaldi S (1983) Numerical simulations of a case of blocking - the effects of orography and land sea contrast. Mon Wea Rev 111(10):2068-2086

Joos F, Bruno M (1996) Pulse response functions are cost-efficient tools to model the link between carbon emissions, atmospheric $\mathrm{CO}_{2}$ and global warming. Phys Chem Earth 21:471-476

Jung T (2005) Systematic errors of the atmospheric circulation in the ECMWF forecasting system. Quart J Roy Meteor Soc 131(607):1045-1073

Karoly DJ, Plumb RA, Ting MF (1989) Examples of the horizontal propagation of quasi-stationary waves. J Atmos Sci 46(18):2802-2811

Kharin VV, Zwiers FW (2003) Improved seasonal probability forecasts. J Clim 16(11):1684-1701

Knaff JA, Landsea CW (1997) An El Niño Southern Oscillation climatology and persistence (CLIPER) forecasting scheme. Wea Forecasting 12(3):633-652

Knutti R, Stocker TF (2002) Limited predictability of the future thermohaline circulation close to an instability threshold. J Climate 15(2):179-186

Knutti R, Stocker TF, Joos F, Plattner G-K (2002) Constraints on radiative forcing and future climate change from observations and climate model ensembles. Nature 416(6882):719-723

Knutti R, Stocker TF, Joos F, Plattner G-K (2003) Probabilistic climate change projections using neural networks. Clim Dyn 21(3-4):257-272

Landsea CW, Knaff JA (2000) How much skill was there in forecasting the very strong 1997-98 El Niño?. Bull Am Meteor Soc 81(9):2107-2119

Latif M, Anderson D, Barnett T, Cane M, Kleeman R, Leetmaa A, O’Brien J, Rosati A, Schneider E (1998) A review of the predictability and prediction of ENSO. J Geophys Res-Oceans 103(C7):14375-14393

Latif M, Roeckner E, Mikolajewicz U, Voss R (2000) Tropical stabilization of the thermohaline circulation in a greenhouse warming simulation. J Climate 13(11):1809-1813

Legras B, Ghil M (1985) Persistent anomalies, blocking and variations in atmospheric predictability. J Atmos Sci 42(5):433-471

Leith CE (1973) The standard error of time-average estimates of climatic means. J Appl Meteor 12:1066-1069

Lin H, Derome J (2004) Nonlinearity of the extratropical response to tropical forcing. J Clim 17:2597-2608

Liu Q (1994) On the definition and persistence of blocking. Tellus 46A(3):286-298

Lott F, Robertson AW, Ghil M (2004a) Mountain torques and Northern Hemisphere low-frequency variability. Part I: Hemispheric aspects. J Atmos Sci 61(11):1259-1271

Lott F, Robertson AW, Ghil M (2004b) Mountain torques and Northern Hemisphere low-frequency variability. Part II: Regional aspects. J Atmos Sci 61(11):1272-1283

Lupo AR, Smith PJ (1995) Climatological features of blocking anticyclones in the Northern-Hemisphere. Tellus 47A(4):439-456

Luterbacher J, Xoplaki E, Dietrich D, Rickli R, Jacobeit J, Beck C, Gyalistras D, Schmutz C, Wanner H (2002) Reconstruction of sea level pressure fields over the Eastern North Atlantic and Europe back to 1500. Clim Dyn 18:545-561

Madden RA (1976) Estimates of the natural variability of time-averaged sea-level pressure. Mon Wea Rev 104:942-952

Maier-Reimer E, Mikolajewicz U (1992) The Hamburg large scale geostrophic ocean general circulation model (Cycle 1). Technical Report 2, Deutsches Klimarechenzentrum.

Manabe S, Stouffer RJ (1996) Low-frequency variability of surface air temperature in a 1000-year integration of a coupled atmosphere-ocean-land surface model. J Climate 9(2):376-393

Manabe S, Strickler RF (1964) Thermal equilibrium of the atmosphere with a convective adjustment. J Atmos Sci 21(4):361-385

Manabe S, Wetherald RT (1967) Thermal equilibrium of the atmosphere with a given distribution of relative humidity. J Atmos Sci 24(3):241-259

Marotzke J, Welander P, Willebrand J (1988) Instability and multiple steady states in a meridional-plane model of the thermohaline circulation. Tellus 40A:162-172 
Mason SJ (2004) On Using "Climatology" as a reference strategy in the brier and ranked probability skill scores. Mon Wea Rev 132:1891-1895

Mason SJ, Mimmack GM (2002) Comparison of some statistical methods of probabilistic forecasting of ENSO. J Clim 15(1):8-29

Mathieu PP, Sutton B, Dong RT, Collins M (2004) Predictability of winter climate over the North Atlantic European region during ENSO events. J Climate 17:1953-1974

Mauritsen T, Källén E (2004) Blocking prediction in an ensemble forecasting system. Tellus A 56(3):218-228

McPhaden MJ (2004) Evolution of the 2002/03 El Niño. Bull Am Meteor Soc 85(5):677-695

McPhaden MJ, Yu X (1999) Equatorial waves and the 1997-1998 El Niño. Geophys Res Lett 26(19):2961-964

Mearns LO, Katz RW, Schneider SH (1984) Extreme high-temperature events - changes in their probabilities with changes in mean temperature. J Clim Appl Met 23(12):1601-1613

Merkel U, Latif M (2002) A high resolution AGCM study of the El Niño impact on the North Atlantic/European sector. Geophys Res Lett 29(9):1291, doi:10.1029/2001GL013726

Molteni F, Tibaldi S (1990) Regimes in the wintertime circulation over northern extratropics. II: Consequences for dynamical predictability. Quart J Roy Meteor Soc 116:1263-1288

Monahan AH, Fyfe JC, Flato GM (2000) A regime view of Northern Hemisphere atmospheric variability and changes under global warming. Geophys Res Lett 27(8):1139-1142

Müller SA, Joos F, Edwards NR, Stocker TF (2006) Water-mass distribution and ventilation time scales in a cost-efficient, 3-dimensional ocean model. J Clim (in press)

Mullen SL (1987) Transient eddy forcing of blocked flows. J Atmos Sci 44:3-22

Mullen SL (1989a) The impact of orography on blocking frequency in a general-circulation model. J Climate 2(12):1554-1560

Mullen SL (1989b) model experiments on the impact of pacific sea surface temperature anomalies on blocking frequency. J Climate 2(9):997-1013

Müller WA, Appenzeller C, Doblas-Reyes FJ, Liniger MA (2005a) A debiased ranked probability skill score to evaluate probabilistic ensemble forecasts with small ensemble sizes. J Clim 18(10):1513-1523

Müller WA, Appenzeller C, Schär C (2005b) Probabilistic seasonal prediction of the winter North Atlantic Oscillation and its impact on near surface temperature. Clim Dyn 24(2-3):213-226

Murphy AH (1969) On the ranked probability skill score. J Appl Meteor 8:988-989

Murphy AH (1971) A note on the ranked probability skill score. J Appl Meteor 10:155-156

Murphy JM, Sexton DMH, Barnett DN, Jones GS, Webb MJ, Collins M, Allen MR, Stainforth DJ (2004) Quantification of modelling uncertaities in a large ensemble of climate change simulations. Nature 430(7001):768-772

Nakićenović N, Alcamo J, Davis G, de Vries B, Fenhann J, Gaffin S, Gregory K, Grübler A, Jung TY, Kram T, La Rovere EL, Michaelis L, Mori S, Morita T, Pepper W, Pitcher H, Price L, Raihi K, Roehrl A, Rogner H-H, Sankovski A, Schlesinger M, Shukla P, Smith S, Swart R, van Rooijen S, Victor N, Dadi Z (2000) IPCC Special Report on Emissions Scenarios. Cambridge, UK and New York, NY, USA: Cambridge University Press. p 599

Nigam S, Lindzen RS (1989) The sensitivity of stationary waves to variations in the basic state zonal flow. J Atmos Sci 46(12):1746-1768

North GR, Cahalan RF, Coakley JA (1981) 'Energy-balance climate models. Rev Geophys Space Phys 19(1):91-121

Oortwijn J (1998) Predictability of the onset of blocking and strong zonal flow regimes. J Atmos Sci 55:973-994

Opsteegh JD, Haarsma RJ, Selten F, Kattenberg A (1998) ECBILT: A dynamic alternative to mixed boundary conditions in ocean models. Tellus 50A:348-367

Palmer TN (1998) Nonlinear dynamics and climate change: rossby's legacy. Bull Am Meteor Soc 79(7):1411-1423

Palmer TN (1993) Extend-range atmospheric prediction and the lorenz model. Bull Am Meteor Soc 74(1):49-65

Palmer TN (1999) A nonlinear dynamical perspective on climate prediction. J Climate 12(2):575-591

Palmer TN, Alessandri A, Andersen U, Cantelaube P, Davey M, Delecluse P, Deque M, Diez E, Doblas-Reyes FJ, Feddersen H, Graham R, Gualdi S, Gueremy JF, Hagedorn R, Hoshen M, Keenlyside N, Latif M, Lazar A, Maisonnave E, Marletto V, Morse AP, Orfila B, Rogel P, Terres JM, Thomson MC (2004) Development of a European multimodel ensemble system for seasonal-to-interannual prediction (DEMETER). Bull Am Meteor Soc 85(6):853-874

Palmer TN, Anderson DLT (1994) The prospects for seasonal forecasting - a review paper. Quart J Roy Meteor Soc 120(518):755-793

Palmer TN, Shukla J (2000) Editorial to DSP/PROVOST special issue. Quart J Roy Meteor Soc 126(567):1989-1990 
Palmer TN, Shutts GJ, Hagedorn R, Doblas-Reyes F, Jung T, Leutbecher M (2005) Representing model uncertainty in weather and climate prediction. Ann Rev Earth and Plan Sci 33:163-193

Pasmanter RA, Timmermann A (2003) Cyclic Markov chains with an application to an intermediate ENSO model. Nonlin Proc Geophys 10:197-210

Pavan V, Doblas-Reyes FJ (2000) Multi-model seasonal hindcasts over the Euro-Atlantic: Skill scores and dynamic features. Clim Dyn 16(8):611-625

Pavan V, Tibaldi S, Brankovic C (2000a) Seasonal prediction of blocking frequency: Results from winter ensemble experiments. Quart J Roy Meteor Soc 126(567):2125 -2142

Pavan V, Molteni F, Brankovic C (2000b) Wintertime variability in the Euro-Atlantic region in observations and in ECMWF seasonal ensemble experiments. Quart J Roy Meteor Soc 126(567):2143-2173

Peixoto JP, Oort AH (1984) Physics of climate. Rev Mod Phys 56(3):365-429

Pelly JL, Hoskins BJ (2003) How well does the ECMWF ensemble prediction system predict blocking?. Quart J Roy Meteor Soc 129(590):1683-1702

Peng SL, Robinson WA, Li SL (2003) Mechanisms for the NAO responses to the North Atlantic SST tripole. J Clim 16(12):1987-2004

Philander SGH (1990) El Niño, La Niña and the Southern Oscillation. Academic Press, San Diego, CA

Ramanathan V, Coakley JA (1978) Climate modelling through radiative-convective models. Rev Geophys Space Phys 16:465-489

Ramaswamy V, Boucher O, Haigh J, Hauglustaine D, Haywood J, Myhre G, Nakajima T, Shi GY, Solomon S (2001) Radiative forcing of climate change. In: Houghton JT, Ding Y, Griggs DJ, Noguer M, van der Linden PJ, Dai X, Maskell K, Johnson CA (eds) Climate Change 2001: The Scientific Basis. Cambridge, UK and New York, NY, USA: Cambridge University Press, Chapt. 6, pp 349-16. Contribution of Working Group I to the Third Assessment Report of the Intergovenmental Panel on Climate Change, p 881

Reilly J, Stone PH, Forest CE, Webster MD, Jacoby HD, Prinn RG (2001) Uncertainty and climate change assessments. Science 293(5529):430-433

Rex DF (1950a) Blocking action in the middle troposphere and its effect upon regional climate. I. An aerological study of blocking. Tellus 2:169-211

Rex DF (1950b) Blocking action in the middle troposphere and its effect upon regional climate. II. The climatology of blocking action. Tellus 2:275-301

Rodwell MJ, Folland CK (2002) Atlantic air-sea interaction and seasonal predictability. Quart J Roy Meteor Soc 128(583):1413-1443

Rodwell MJ, Rowell DP, Folland CK (1999) Oceanic forcing of the wintertime North Atlantic Oscillation and European climate. Nature 398(6725):320-323

Saltzman B (1978) A survey of statistical-dynamical models of the terrestrial climate. Adv Geophys 20:183-303

Saunders MA, Qian BD (2002) Seasonal predictability of the winter NAO from North Atlantic sea surface temperatures. Geophys Res Lett 29(22):2049, doi:10.1029/2002GL014952

Sausen R, König W, Sielmann F (1995) Analysis of blocking events from observations and ECHAM model simulations. Tellus 47(4):421-438

Scherrer SC, Croci-Maspoli M, Schwierz C, Appenzeller C (2006) Two-dimensional indices of atmospheric blocking and their statistical relationship with winter climate patterns in the Euro-Atlantic region. Int $\mathbf{J}$ Clim 26(2):233-249

Schmittner A, Appenzeller C, Stocker TF (2000) Enhanced Atlantic freshwater export during El Niño. Geophys Res Lett 27:1163-1166

Schneider SH (2000) Adaptation: sensitivity to natural variability, agent assumptions and dynamic climate changes. Climatic Change 45(1):203-221

Schneider SH (2001) What is 'dangerous' climate change? Nature 411(6833):17-19

Schwierz C (2001) Interactions of greenland-scale orography and extra-tropical synoptic-scale flow. Ph.D. thesis, ETH Zürich, Institute for Atmospheric and Climate Science. Dissertation Nr. 14356

Schwierz C, Croci-Maspoli M, Davies HC (2004) A perspicacious indicator of atmospheric blocking. Geophys Res Lett 31(6):L06125, doi: 10.1029/2003GL019341

Sellers WD (1969) A global climatic model based on the energy balance of the earth-atmosphere system. J Appl Meteorol 8:392-400

Shabbar A, Huang J, Higuchi K (2001) The relationship between the wintertime North Atlantic Oscillation and blocking episodes in the Northern Atlantic. Int J Clim 21(3):355

Shukla J, Anderson J, Baumhefner D, Brankovic C, Chang Y, Kalnay E, Marx L, Palmer T, Paolino D, Ploshay J, Schubert S, Straus D, Suarez M, Tribbia J (2000) Dynamical seasonal prediction. Bull Am Meteor Soc 81(11):2593-2606

Shutts GJ (1983) The propagation of eddies in diffluent jetstreams: Eddy vorticity forcing of "blocking" flow fields. Quart J Roy Meteor Soc 109:737-761 
Simmons AJ, Wallace JM, Branstator GW (1983) Barotropic wave propagation and instability, and atmospheric teleconnection patterns. J Atmos Sci 40(6):1363-1392

Smith LA (2002) What might we learn from climate forecasts? P Natl Acad Sci USA 99(Suppl. 1):2487-2492. Suppl. 1.

Stainforth DA, Aina T, Christensen C, Collins M, Faull N, Frame DJ, Kettleborough JA, Knight S, Martin A, Murphy JM, Plani C, Sexton D, Smith LA, Spicer RA, Thorpe AJ, Allen MR (2005) Uncertainty in predictions of climate change response to rising levels of greenhouse gases. Nature 433:403-406

Stephenson DB (2000) Is the North Atlantic Oscillation a random walk? Int J Climatol 10:1-18

Stephenson DB, Pavan V, Bojariu R (2000) Is the North Atlantic Oscillation a random walk? Int J Climatol 20(1):1-18

Stern W, Miyakoda K (1995) Feasibility of seasonal forecasts inferred from multiple GCM simulations. J Clim 8(5):1071-1085

Stocker TF, Wright DG, Mysak LA (1992) A zonally averaged, coupled ocean-atmosphere model for paleoclimate studies. J Clim 5(1):773-797

Stocker TF, Knutti R (2003) Do simplified climate models have any useful skill? CLIVAR Exchanges 8(1):7-10

Stocker TF, Marchal O (2001) Recent progress in paleoclimate modeling: Climate models of reduced complexity. PAGES News 9(1):4-7

Stocker TF, Schmittner A (1997) Influence of $\mathrm{CO}_{2}$ emission rates on the stability of the thermohaline circulation. Nature 388(6645):862-865

Stott PA, Kettleborough JA (2002) Oringins and estimates of uncertainty in predictions of twenty-first century temperature rise. Nature 416(6882):723-726

Stouffer RJ, Hegerl G, Tett S (2000) A comparison of surface air temperature variability in three 1000-yr coupled ocean-atmosphere model integrations. J Climate 13(3):513-537

Stouffer RJ, Manabe S (1999) Response of a coupled ocean-atmosphere model to increasing atmospheric carbon dioxide: Sensitivity to the rate of increase. J Climate 12(8: Part I):2224-2237

Sutton R (2005) Informing adaptation: New challenges for the climate modelling community. Weather 60(7):186-189

Swets JA (1973) The relative operating characteristic in psychology. Science 182:990-1000

Thompson PD (1977) How to improve accuracy by combining independent forecasts. Mon Wea Rev 105:228-229

Thompson DWJ, Wallace JM (2001) Regional climate impacts of the Northern Hemisphere Annular Mode. Science 293(5527):85-89

Tibaldi S, D'Andrea F, Tosi E, Roeckner E (1997) Climatology of Northern Hemisphere blocking in the ECHAM model. Climate Dyn 13:649-666

Tibaldi S, Tosi E, Navarra A, Pedulli L (1994) Northern and Southern-Hemisphere seasonal variability of blocking frequency and predictability. Mon Wea Rev 122(9):1971-2003

Tracton MS, Kalnay E (1993) Operational ensemble prediction at the national meteorological center practical aspects. Wea Forecasting 8(3):379-398

Trenberth KE, Branstator GW, Karoly D, Kumar A, Lau NC, Ropelewski C (1998) Progress during TOGA in understanding and modeling global teleconnections associated with tropical sea surface temperatures. J Geophys Res-Oceans 103(C7):14291-14324

Trenberth KE, Hurrell JW (1994) Decadal atmosphere-ocean variations in the Pacific. Clim Dyn 9(6):303-319

Trevisan A, Pancotti F, Molteni F (2001) Ensemble prediction in a model with flow regimes. Quart J Roy Meteor Soc 127(572):343-358

Trigo RM, Trigo IF, DaCamara CC, Osborn TJ (2004) Climate impact of the European winter blocking episodes from the NCEP/NCAR Reanalyses. Clim Dyn 23(1)

Tsou CH, Smith PJ (1990) The role of synoptic/planetary-scale interactions during the development of a blocking anticyclone. Tellus 42A:174-193

Tung KK, Lindzen RS (1979) A theory of stationary long waves. Part I: A simple theory of blocking. Mon Wea Rev 107(6):714-734

van Oldenborgh GJ, Balmaseda M, Ferranti L, Stockdale T, Anderson D (2003) Did the ECMWF seasonal forecast model outperform a statistical model over the last 15 years?. Vol. 418 of ECMWF Technical Memorandum. ECMWF, p 32

van Oldenborgh GJ, Burgers G, Klein Tank A (2000) On the El Niño teleconnection to spring precipitation in Europe. Int J Climatol 20:565-574

Vautard R, Legras B, Déqué M (1988) On the source of midlatitude low-frequency variability. 1. A statistical approach to persistence. J Atmos Sci 45(20):2811-2843

Vitart F, Balmaseda MA, Ferranti L, Anderson D (2003) Westerly wind events and the 1997/98 El Niño event in the ECMWF seasonal forecasting system: A case study. J Clim 16(19):3153-3170 
Watson JS, Colucci SJ (2002) Evaluation of ensemble predictions of blocking in the NCEP global spectral model. Mon Wea Rev 130(12):3008-3021

Weaver AJ, Zwiers FW (2000) Uncertainty in climate change. Nature 407(6804):571-572

Wiedenmann JM, Lupo AR, Mokhov II, TEA (2002) The climatology of blocking anticyclones for the Northern and Southern Hemispheres: Block intensity as a diagnostic. J Climate 15(23):3459-3473

Wigley TML, Raper SCB (2001) Interpretation of high projections for global-mean warming. Science 293(5529):451-454

Wilks DS (1995) Statistical methods in the atmospheric sciences, Vol. 59 of International Geophysics Series. Academic Press

Wright DG, Stocker TF (1991) A zonally averaged ocean model for the thermohaline circulation. Part I: Model development and flow dynamics. J Phys Oceanogr 21(12):1713-1724

Wunsch C (1999) The interpretation of short climate records, with comments on the North Atlantic Oscillation and Southern Oscillations. Bull Am Met Soc 80(2):245-255

Yamane S, Yoden S (1997) Predictability variation and quasi-stationary states in simple non-linear systems. J Met Soc Jap 75(2):557-568

Zheng X, Frederiksen CS (2004) Variability of seasonal-mean fields arising from intraseasonal variability: part 1, methodology. Clim Dyn 23(2):177-191

Zwiers FW (2002) The 20-year forecast. Nature 416(6882):690-691 